\title{
Article \\ Repowering Coal Power in China by Nuclear Energy-Implementation Strategy and Potential
}

\author{
Song Xu ${ }^{1}\left(\mathbb{D}\right.$, Yiu Hin Martin Lu ${ }^{1}$, Meiheriayi Mutailipu ${ }^{2}$, Kanti Yan ${ }^{2}$, Yaoli Zhang ${ }^{1,3, * \mathbb{C}}$ and Staffan Qvist ${ }^{4, *(\mathbb{C})}$ \\ 1 College of Energy, Xiamen University, Xiamen 361001, China; 32420191152366@stu.xmu.edu.cn (S.X.); \\ martinnnlu@outlook.com (Y.H.M.L.) \\ 2 Department of Electrical Engineering, Xinjiang University, Urumchi 830017, China; \\ mhriay@xju.edu.cn (M.M.); 107552101427@stu.xju.edu.cn (K.Y.) \\ 3 Research Center for Nuclear Engineering, Xiamen 361001, China \\ 4 Qvist Consulting Limited, Maidenhead SL6 8EW, UK \\ * Correspondence: zhangyl@xmu.edu.cn (Y.Z.); staffanq@gmail.com (S.Q.)
}

Citation: Xu, S.; Lu, Y.H.M.; Mutailipu, M.; Yan, K.; Zhang, Y.; Qvist, S. Repowering Coal Power in China by Nuclear EnergyImplementation Strategy and Potential. Energies 2022, 15, 1072. https://doi.org/10.3390/ en15031072

Academic Editor: Dan Gabriel Cacuci

Received: 22 December 2021

Accepted: 28 January 2022

Published: 31 January 2022

Publisher's Note: MDPI stays neutral with regard to jurisdictional claims in published maps and institutional affiliations.

Copyright: (C) 2022 by the authors. Licensee MDPI, Basel, Switzerland. This article is an open access article distributed under the terms and conditions of the Creative Commons Attribution (CC BY) license (https:// creativecommons.org/licenses/by/ $4.0 /)$.

\begin{abstract}
This article discusses a sustainable low-carbon development strategy that uses nuclear heat sources to replace coal boilers at existing coal power plants in China, to help support a resource and cost-effective low-carbon development. Based on the local situation in China, a three-stage strategy to explore the potential of repowering coal power by nuclear energy is proposed. The main focus of this study is to conduct a more detailed exploration of the 1st stage of this strategy, which includes coal plants located on the coast in regions that already have nuclear power installations. The study makes use of HTR-PM modular reactor for retrofit analysis for the types of coal units present in 1st stage of the strategy. The results show that: 1 . There is a technical and economic basis for exploring nuclear power retrofit decarbonization. This conclusion is backed up by on-site transformation analysis and demonstration of the conversion of representative plant units to ensure the validity and reliability of the data. 2. This research provides a new pathway for the problem of stranded assets in China's power sector decarbonization. The use of HTR-PM modules for retrofit can save up to 1200 billion \$ as well as retaining local jobs and economic activity in areas currently hosting coal plants, which brings to society great economic and social benefits.
\end{abstract}

Keywords: retrofit; three-stage strategy; HTR-PM; stranded assets; economic benefits

\section{Introduction}

\subsection{Background and Challenges of Retrofit Decarbonization}

China's rapidly increasing power consumption, based primarily on coal, has brought severe challenges to national energy security, climate change, and environmental pollution control [1,2]. In the context of tightening of resource constraints, global warming, air pollution, and severe damage to the environment [3,4], achieving "carbon neutrality" and moving away from coal as a primary source of energy have become a core focus for China going forward.

The purpose of this study is to evaluate the role of existing coal power assets in China's future low-carbon power system. The leaders of the Chinese government proposed "Dual carbon" goals in 2020 [5], and started to introduce electricity market reform. These marketbased reforms aim to improve the efficiency of both dispatch and investments in the power sector [6], and to help facilitate decarbonization. However, there are some challenges in this process [7], mainly in the planning, investment, and operation of low-carbon power systems. It is not only necessary to ensure the reliable operation of the power system, but also to consider the impact on the environment, health, biodiversity, and other factors during the transition. How to best coordinate the economics of the transformation of new and old technologies and the impact of new technologies on the old power system, including employment opportunities, has proven difficult for policymakers. 


\subsection{Current Focus of Chinese Retrofit Strategy for Decarbonization}

At present, China's power sector operates a total of 1037 coal-fired power plants [8], with nearly 3000 individual units, and 460 units planned and under construction, with a total installed capacity of approximately $1131 \mathrm{GWe}$, as shown in Figure 1. All data come from the Global Energy Tracker [8]. A coal power plant is usually composed of multiple units, and each unit is composed of a separate coal-fired boiler and steam turbine generator unit. Not all coal-fired power generation units in China are suitable for retrofit decarbonization. Some units have been running for too long and have long passed their effective age. Some units are small in capacity, making the economic case for retrofitting difficult to justify. The conditions applied to define which coal plants are of interest of retrofit studies are defined in Table 1.

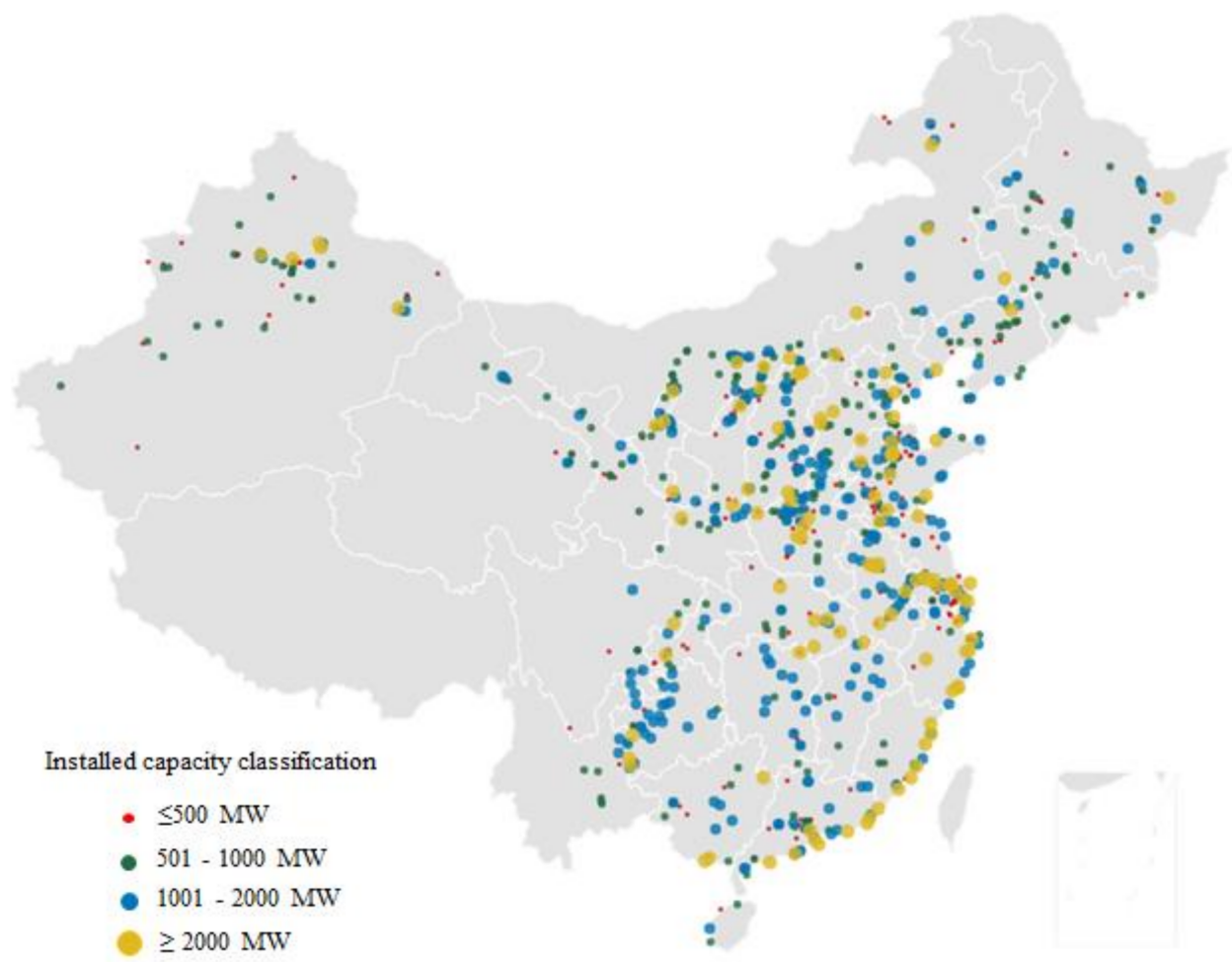

Figure 1. Location and size of existing coal plants in China.

Applying the two conditions (age and size) in the table to the data of China's coal power plants, we found that a total of 2264 coal units can be used for nuclear power retrofit decarbonization, and the total retrofit decarbonization potential reaches $906 \mathrm{GW}$. The remaining capacity is more suitable for decommissioning and being completely replaced by other low-carbon energy technologies.

The relevant effective-age cutoff relevant for repowering analysis is in the span of 15-20 years due to the total technical lifetime of individual major components that could remain in use in an existing coal power station, which varies from $20-50$ years. This indicates that these components would be so depreciated by the time the first repowering projects could be completed (in 5-10 years from now) that they would anyway need to be rapidly replaced at that point. Therefore, plants that have not been modernized within the last 15-20 years are not generally of interest for repowering. Due to the very large number of young coal plan units in China, the lower value of 15 years was applied in this study. 
Table 1. Threshold requirements for coal unit inclusion in retrofit decarbonization analysis.

\begin{tabular}{|c|c|c|}
\hline Parameter & Value & Motivation \\
\hline $\begin{array}{l}\text { Maximum current effective } \\
\text { age of relevant equipment }\end{array}$ & $\begin{array}{l}20 \text { years } \\
\text { (15 years in China) }\end{array}$ & $\begin{array}{l}\text { The main motivation for the } \\
\text { retrofit decarbonization is to } \\
\text { make full use of the remaining } \\
\text { service life of existing } \\
\text { equipment and avoid } \\
\text { stranding of existing assets. } \\
\text { According to estimates of the } \\
\text { life of various equipment in } \\
\text { thermal power plants, units } \\
\text { over } 20 \text { years are no longer } \\
\text { considered for anything } \\
\text { except for the re-use of the site } \\
\text { itself and its grid connection. } \\
\text { Given the relatively young } \\
\text { age of the Chinese coal power } \\
\text { fleet, a value of } 15 \text { years is } \\
\text { applied in the analysis in } \\
\text { Chapter } 4 \text { of this study. }\end{array}$ \\
\hline Rated capacity range & 250-2000 MWth & $\begin{array}{l}\text { The unit model selected for } \\
\text { the retrofit project is HTR-PM, } \\
\text { and the thermal power of a } \\
\text { single unit is } 250 \mathrm{MWth} \text {, so } \\
\text { the transformation must meet } \\
\text { the power requirements of the } \\
\text { unit. In addition, units with } \\
\text { electric power less than } \\
50 \text { MWe are usually } \\
\text { small-scale power stations or } \\
\text { factory-owned power stations, } \\
\text { which are difficult to retrofit. }\end{array}$ \\
\hline
\end{tabular}

From the perspective of China's current energy system, although existing and underconstruction plants could continue operating in the 2060s, the climate policy focused on decarbonization means most have to either be decommissioned, retrofit with highly effective carbon capture systems, or be repowered with low-carbon heat sources such as nuclear in the relatively near future.

Current decarbonization proposals for coal-fired power plants are based on two main approaches: either decommission coal-fired plants as early as possible or reduce direct emissions by implementing carbon capture systems. Hoseinzadeh et al. [9] explore the energy and exergy analysis of coal-fired power plants and provide instructive recommendations for improving energy system performance. Liu et al. [10] analyzed the development of carbon capture, utilization, and storage and found it could play an important role in the pathway to deep decarbonization. Wang et al. [11] assessed the potential of China's transition to low-carbon development and elaborated on technology choices. Wen et al. [12] conducted a quantitative analysis of China's power system based on a dynamic simulation model, and evaluated the economic cost and carbon emissions of each transitional technology. Cheng et al. [13] used multi-energy systems to achieve regional low-carbon development, highlighting that multi-energy systems can only achieve optimal planning for specific regions. In addition, research on the power system has shown [14-18] that an optimized decarbonization strategy includes improving energy efficiency and the introduction of carbon emissions trading. Apart from the existing two approaches, a third option is possible: repowering of coal power units with new low-carbon technologies such as nuclear energy. The "dual carbon" goal is not to eliminate coal power. Considering the development of current mature thermal power generation technology and gas turbine technology in China, it is a pity to abandon coal power technology. This third option could 
avoid stranding existing assets $[19,20]$, avoid local unemployment, while reducing the cost of transition to a zero-emission energy system.

\subsection{Motivation and Contribution}

Energy decarbonization involves both shutting down emission sources such as coal power plants and replacing them with emission-free energy sources. Retrofitting decarbonization has the unique potential to do both at once. The research outputs of this paper is meant to help ease decarbonization, for example by reducing costs, increasing acceptance, and tackling barriers such as the risk of stranded assets in existing infrastructure. In practical terms, the main outcomes will be:

1. From a political point of view, this research provides the technical and economic foundation for retrofit decarbonization of coal plants by nuclear reactors (specifically HTR-PM) to major public utilities in China that are currently operating or constructing coal plants. It can play an important role in guiding future energy planning to invest in sustainable energy infrastructure. In addition, the use of actual plant data for case studies can form the basis for concrete near-term action plans.

2. From a scientific methodological point of view, it provides validated input data to Chinese energy system and decarbonization pathway modelers to include the technology option of retrofit decarbonized coal power plants in their studies and pathways, highlighting its regional and national potential as part of cost-optimal decarbonization plans. Balancing economics and comprehensive energy efficiency in retrofit decarbonization is an important challenge, especially for energy systems in coastal cities. There is still a knowledge gap in understanding the best transformation path. This research can help fill the gap in the domestic retrofit decarbonization of thermal power in China, and provide reference for the retrofit decarbonization and optimized operation of power systems.

The paper is organized as follows. Section 2 introduces the three-stage strategy. Section 3 reports the technical characteristics of 1st-Phase coastal coal cower plants in China. Section 4 expounds the retrofit decarbonization with nuclear reactors in China. Section 5 presents the case study of the representative coal power plant units. Section 6 gives the conclusions and discussion.

\section{Three-Stage Strategy for Coal Power Repowering in China}

In the planning for retrofit decarbonization of coal power plants, the first step is to review the site selection and the site applicability for the replacement heat source, in this case small modular nuclear reactors. In China, all commercial nuclear power plants have so far been built by the sea, and inland nuclear power plants remain in the planning stage. There are three main reasons:

a. From a technical point of view, thermal power plants such as nuclear and coal units are similar, but with different means of generating the steam. Theoretically, the cooling system of a coal power plant can be used to cool a nuclear power with the same steam characteristics. If large amounts of cooling water is not available at the site, coal plants in China have been designed to use hybrid or even dry cooling systems. This type of technology is less proven and may entail a higher risk of failure than the simple and robust traditional water-cooling systems. For nuclear power, the industry has so far preferred traditional cooling systems, which has acted to limit the development of nuclear power in China's inland to date.

b. From an economic point of view, the economy of China's coastal urban areas is more developed than that of inland cities, and their load energy demand is greater. The construction of nuclear power plants along the coast can effectively reduce the cost of transmission expansion.

c. The public's attitude toward nuclear power directly affects the construction and operation of nuclear power. If the public's awareness and understanding is low, it is easy for local residents to be hesitant to approve of local nuclear power plants due to 
the perceived environmental and health risks. China's per capita water resources are actually very scarce. If the only large local water source in an inland community is to be used for cooling by a nuclear power plant, people may protest out of fear and a lack of knowledge about what this entails. China's overarching priority is political stability. Even if nuclear power plants have good economic and environmental effects, if their introduction in a new area may threaten political stability, it is seen as not worth the risk.

Therefore, from the perspectives of security, economy, and political environment, a staged approach for the repowering of coal plants by nuclear is needed. We suggest the following three main steps:

1. The first phase is to repower coal power plants located directly on the coast. As the first batch of projects, these will be used as demonstration projects for subsequent stages.

2. The second phase is the transformation of coal plants near inland cities close to the coast inside coastal provinces that already have commercial nuclear power plants.

3. Finally, the retrofit decarbonization of coal power plants in inland cities is carried out. The bulk of Chinese coal power capacity is in this third stage. The retrofit decarbonization of these plants is of great significance to China's carbon neutrality goal.

This strategy is shown in Figure 2 below.

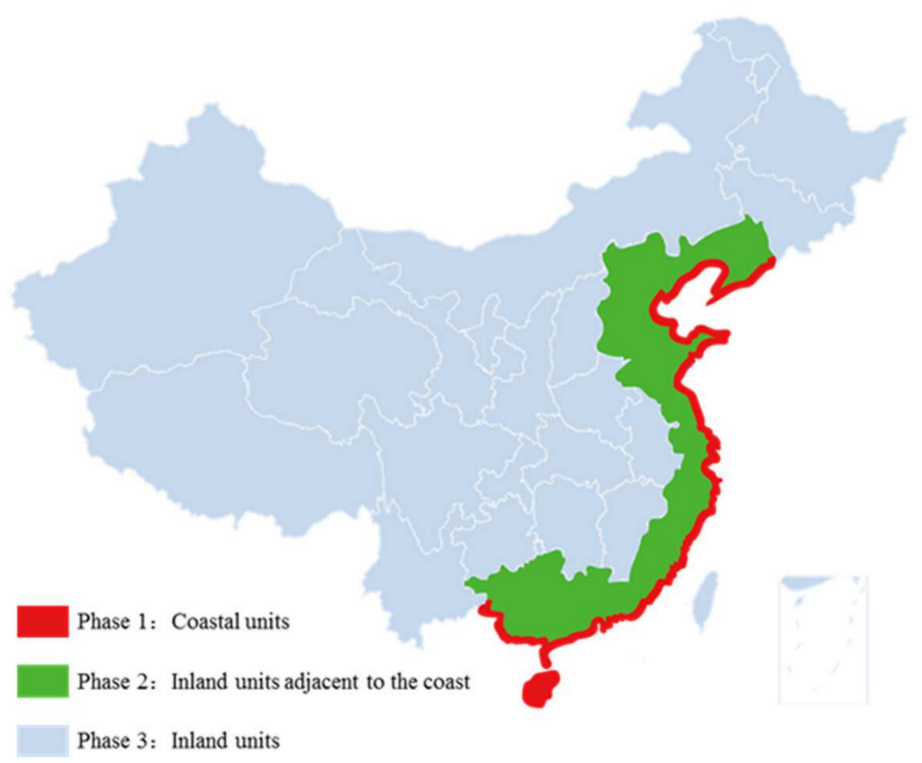

Figure 2. Regional distribution of China's three-step approach.

Implementation of the first stage will start in the very near term, because many existing coastal thermal power plants meet the site selection requirements for nuclear power plants. China also has sufficient experience to operate and construct coastal nuclear power plants. In terms of timing, the main pre-requisite to start this phase is the successful initial commercial operation of the HTR-PM demonstration units, which is expected to start in Q1 2022 following initial criticality in September 2021 and grid connection in December 2021. Thus, the first repowering projects in the first phase could realistically move to implementation planning by the end of 2022 and be in operation by Q2 2026.

The second phase is the repowering of plants in or near inland cities of coastal provinces. These border coastal cities have relatively abundant water resources. Second, they are relatively short distance from the electricity load area and relatively convenient for electricity transmission. At present, China does not have experience in the construction of non-coastal nuclear power units. If the second stage of nuclear power transformation and decarbonization can be achieved, the following problems will need to be solved: 
- Due to technical and political reasons, China lacks experience with closed-loop condenser cooling system designs for nuclear power. China does not yet have inland nuclear power plants that use cooling towers and will need to develop expertise and experience in nuclear power plant construction with cooling tower-based condenser cooling designs. Since this is an industry standard approach for inland nuclear plants internationally, and used at hundreds of other thermal power plants in China, this should be a relatively minor challenge.

- Safety assessment studies are required to quantify any potential disadvantages of the inland site relative to coastal sites. Therefore, any differences in the approach regarding how to deal with the occurrence of the accident source item when siting inland must be resolved at this stage.

- Additional research is required to determine how the economics will change as the transformation project penetrates further inland. If there is no significant change in the cost, this indicates that China's inland nuclear power plants can be cost-effectively repowered as well.

Countries such as the United States and France have many inland nuclear power plants, and they have accumulated considerable operating experience in solving problems related to limited cooling water sources, emission control, environmental monitoring, and thermal pollution control. China can formulate a nuclear power development strategy that suits China's national conditions by learning from the good practices and advanced experience of other countries and to succeed in the second and third stages of the repowering project.

The capacity (in terms of existing coal power plants to be repowered) of possible repowering in each step is shown in Figure 3 below. In the first stage, there are 175 coalfired power generating units with a total capacity of about $79 \mathrm{GW}$. For the second stage, the transformation potential of inland plants near the coast, the total capacity is $184 \mathrm{GW}$. The effective age of nearly $80 \%$ of the capacity in the 2 nd stage is less than 7 years today. Finally, the third inland phase involves the possible repowering of up to $643 \mathrm{GW}$ of capacity. Moreover, $488 \mathrm{GW}$ of existing coal plant capacity cannot realistically be repowered and should instead be replaced by a mix of low-carbon power technologies, possibly re-using the site and grid connection but none of the other equipment.

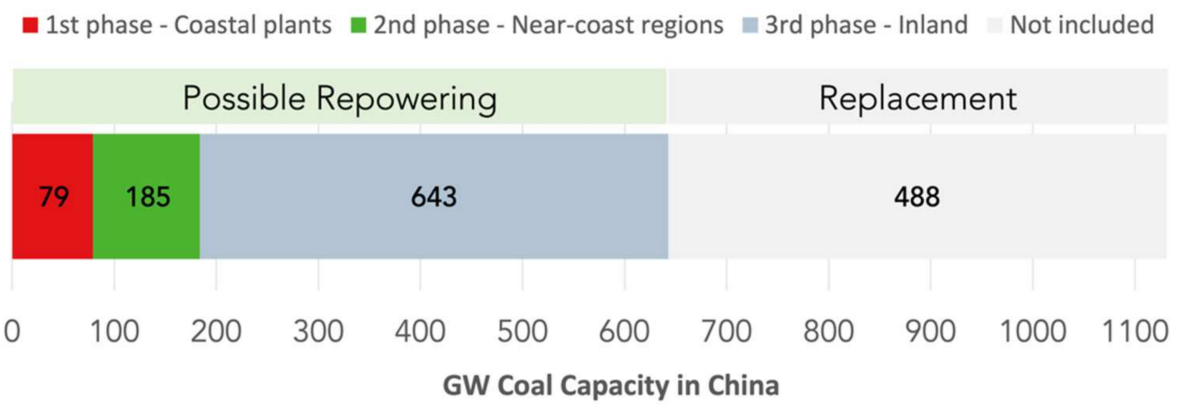

Figure 3. Capacity distribution of China's three-step approach.

If the HTR-PM initial commercial operation is successful and the idea of repowering is adopted at a political level, it is conceivable to target the milestones stated in Table 2 for the repowering project, with the first repowered coastal demo unit in operation around Q2 2026. 
Table 2. Possible milestones of the 3-phase repowering strategy for China.

\begin{tabular}{cl}
\hline \multicolumn{1}{c}{ Date } & \multicolumn{1}{c}{ Milestone } \\
\hline Q3 2021 & HTR-PM initial criticality \\
Q4 2021 & Coal repowering strategy for China suggested \\
Q1 2022 & HTR-PM power operation \\
Q2 2022 & First repowering demo projects in 1st phase selected \\
Q4 2022 & HTR-PM technology verified by power operation \\
Q2 2024 & First projects in 2nd phase selected \\
Q1 2026 & First repowering demo project in 1st phase in operation \\
Q1 2026 & First repowering projects in 3rd phase selected \\
Q1 2028 & First repowering project in 2nd phase in operation \\
Q2 2030 & First repowering project in 3rd phase in operation \\
\hline
\end{tabular}

\section{Technical Characteristics of 1st-Phase Coastal Coal Power Plants in China}

\subsection{Effective Age of the Coal Units}

Figure A1 (see Appendix A) shows the age distribution diagram (by capacity) for the 175 units included in the first phase. Since this study focuses on the nuclear power retrofit decarbonization of coal power plants, based on the Ref. [20], the maximum current effective age is set at 15 years. This is because nuclear power projects are restricted by various factors such as political support, project permits, land approvals, and urban planning, which affect the progress of the project.

\subsection{Steam Parameters}

In the 175 coal-fired power plants in coastal cities, three quarters operate a peak (live) steam temperature in the range of $540-579{ }^{\circ} \mathrm{C}$. There are only 7 units operating at lower steam temperatures $\left(535\right.$ and $\left.538^{\circ} \mathrm{C}\right)$. The specific temperature distribution is shown in Figure 4.

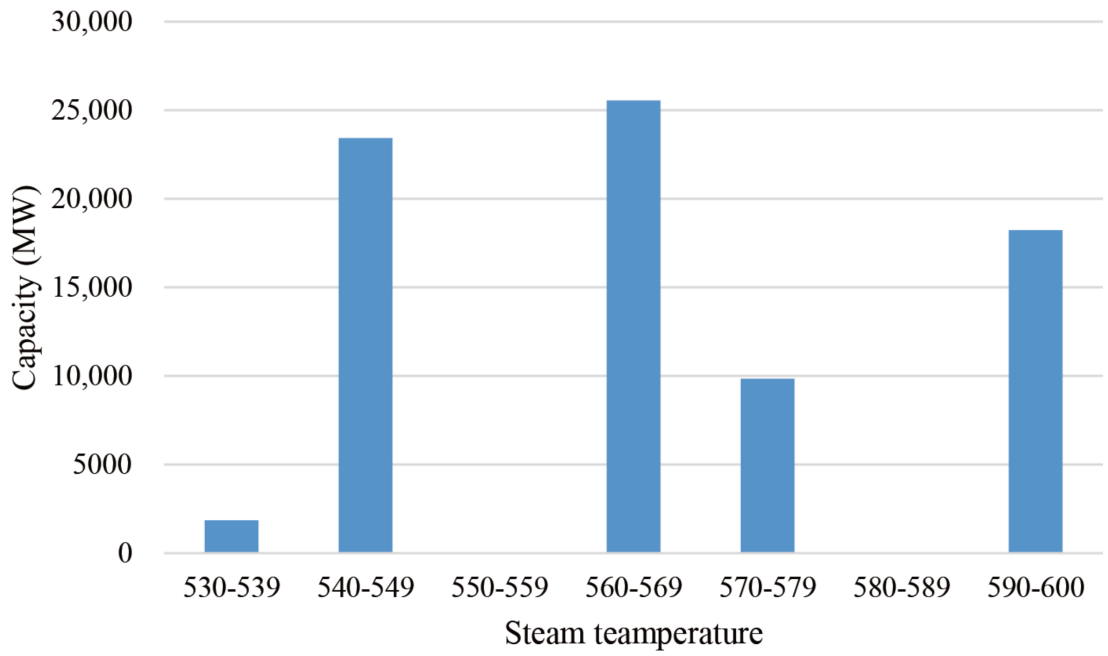

Figure 4. Maximum steam temperature of modern ( $<15$ y) large ( $>50 \mathrm{MWe})$ China coal units.

In addition to temperature, another important parameter of power plant steam cycle is steam pressure. Figure 5 shows the live steam pressure of these 175 coal power units. 


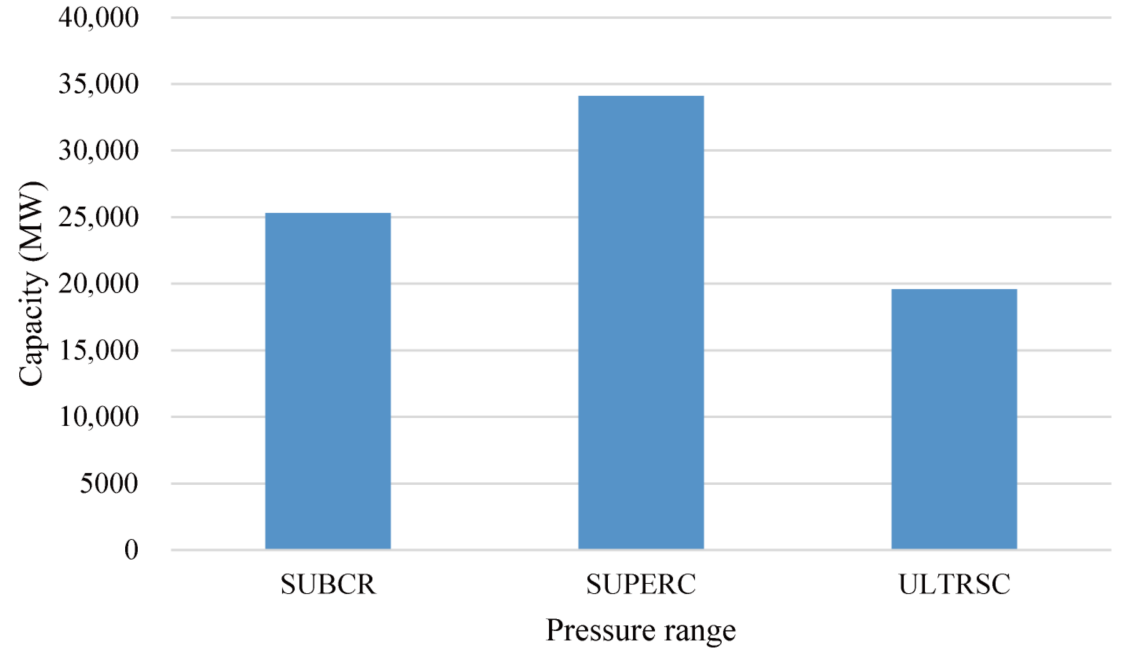

Figure 5. Live steam pressure of coal power plants in China.

\subsection{Unit Categorization}

Among the units included in the first phase, the rated power of a single unit is generally $300 \mathrm{MW}, 350 \mathrm{MW}, 600 \mathrm{MW}$, and $660 \mathrm{MW}$. For the purpose of retrofit decarbonization analysis, the 175 coal power plants in coastal cities are subdivided into three categories, as defined in Table 3.

Table 3. Categorization of China Coal Power Units.

\begin{tabular}{|c|c|c|}
\hline Category & Description & Technical Details \\
\hline 1. Small units & $\begin{array}{l}\text { Units with an individual } \\
\text { electric capacity of less than } \\
200 \mathrm{MW} \text {. } \\
\text { Most individual unit capacity: } \\
150 \mathrm{MW} \text {. }\end{array}$ & $\begin{array}{l}\text { Capacity: } 6145 \mathrm{MW} \\
\text { Number of units: } 10 \\
\text { Subcritical steam cycles } \\
\text { Live steam temperature: } \\
535-549^{\circ} \mathrm{C}\end{array}$ \\
\hline 2. Medium units & $\begin{array}{l}\text { In the } 300-350 \mathrm{MW} \text { range. } \\
\text { Individual unit capacity: } \\
300 \mathrm{MW}, 330 \mathrm{MW}, 350 \mathrm{MW} \text {. }\end{array}$ & $\begin{array}{l}\text { Capacity: } 27,900 \mathrm{MW} \\
\text { Number of units: } 86 \\
69 \% \text { of units: subcritical } \\
\text { steam cycles } \\
31 \% \text { of units: supercritical } \\
\text { steam cycles } \\
\text { Live steam temperature: } \\
535-579{ }^{\circ} \mathrm{C}\end{array}$ \\
\hline 3. Large units & $\begin{array}{l}\text { Large units are defined as } \\
\text { having a capacity larger than } \\
600 \mathrm{MW} \text {. } \\
\text { Individual unit capacity: } \\
600 \mathrm{MW}, 660 \mathrm{MW} \text {. }\end{array}$ & $\begin{array}{l}\text { Capacity: } 49,590 \mathrm{MW} \\
\text { Number of units: } 79 \\
11 \% \text { of units: Subcritical steam } \\
\text { cycles } \\
51 \% \text { of units: supercritical } \\
\text { steam cycles } \\
38 \% \text { of units: } \\
\text { ultra-supercritical steam } \\
\text { cycles } \\
\text { Live steam temperature: } \\
540-60{ }^{\circ} \mathrm{C}\end{array}$ \\
\hline
\end{tabular}

Figure A2 (see Appendix A) shows the classification of the 175 coal power plants in the table. The red ones on the left represent small units, the green ones in the middle represent medium units, and the gray ones on the right represent large power plants. In this study, the use of coal power plants is not subdivided, mainly because coal power plants 
with different unit capacity have the ability to supply heat, regardless of unit capacity. The use of coal power plants considered in this paper can be electricity-only, industrial $\mathrm{CHP}$, district heat CHP or combined CHP. Figure 6 shows the capacity of the units used in different categories.

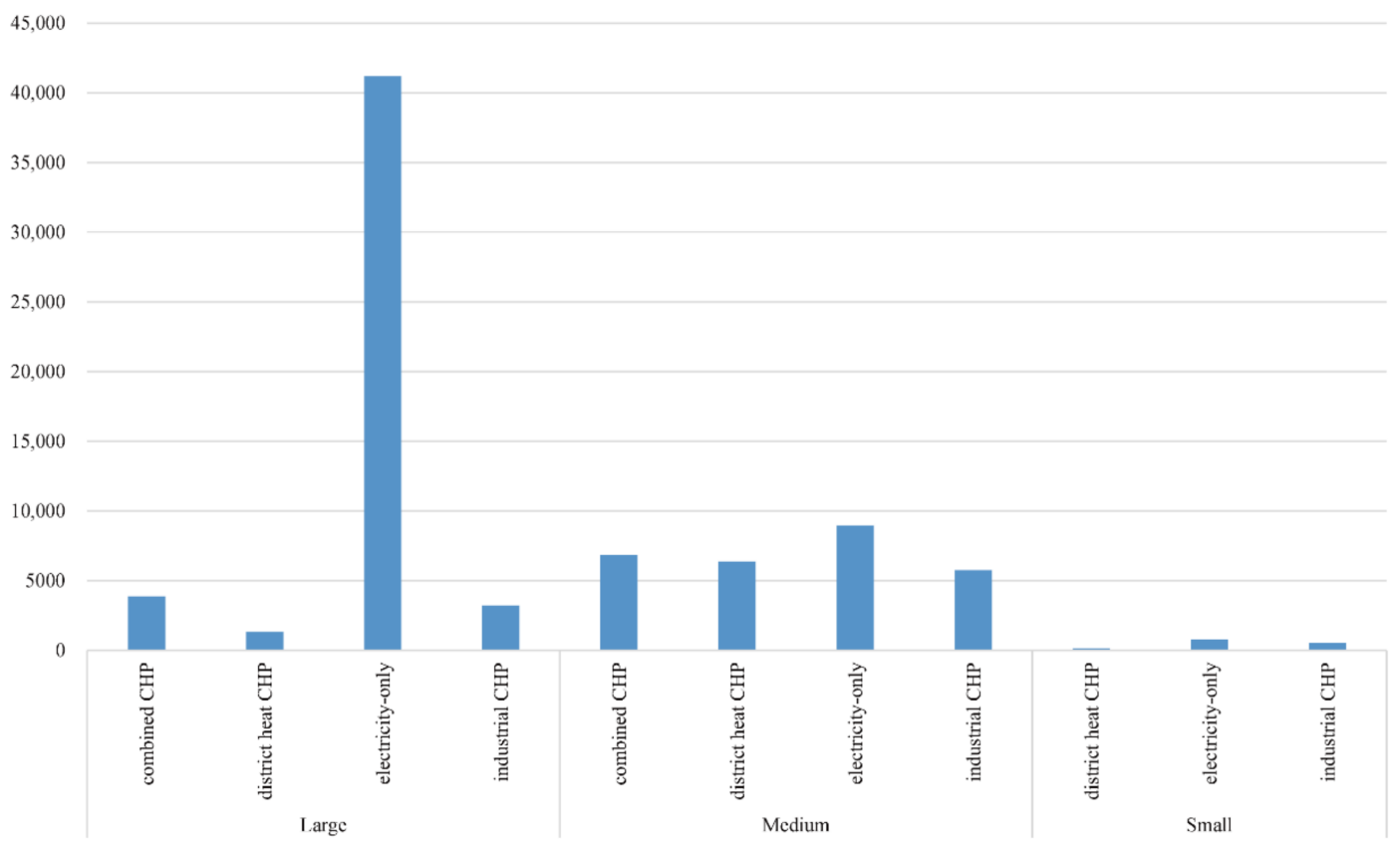

Figure 6. Unit usage under different categories.

As can be seen from the above figure, the electricity-only capacity of large units dominates in the first phase. Among the medium units, coal-fired power units have diverse uses, and the proportions of the four types of uses are basically the same. For smaller units, most of them are used for electricity-only and industrial CHP. Most of the units used in the industrial CHP category are captive units in the factory for industrial production purposes.

\section{Retrofit Decarbonization with Nuclear Reactors in China}

\subsection{Advanced Reactors under Development in China}

China is also developing and demonstrating several types of advanced nuclear reactor technology simultaneously [21]. Table 4 shows some of the most advanced concepts across six reactor technology families that all are able to produce steam of similar parameters (temperature and pressure) as existing Chinese coal power plants.

Table 4. Advanced reactors under development in China.

\begin{tabular}{llllll}
\hline Acronym & Design Org. & Coolant & $\begin{array}{l}\text { Steam } \\
\text { Temperature }\left({ }^{\circ} \mathbf{C}\right)\end{array}$ & Type & Status \\
\hline HTR-PM & Tsinghua University & Helium & $540-600$ & GCR & In operation \\
CRF-600 & CIAE & Sodium & $500-550$ & SFR & In construction \\
CLEAR-I & INEST & Lead Bismuth Eutectic & $480-570$ & LFR & Experimental \\
CSR1000 & NPIC & Light Water & $510-625$ & SCWR & Demonstration \\
TMSR & SINAP & LiF-BeF $_{2}$ & $672-700$ & MSR & In construction \\
\hline
\end{tabular}

The HTR-PM is a small modular high-temperature gas-cooled reactor (HTGR) designed by the Institute of Nuclear and New Energy Technology (INET) of Tsinghua University [22]. The first HTR-PM nuclear power plant built in Shidaowan, Shandong Province, 
China has entered the final stage of construction. The goal is to achieve power production and commercial operation in Q1 2022.

CRF-600 is the second-stage sodium-cooled reactor researched by the Fast Reactor of the China Institute of Atomic Energy (CIAE). It was developed on the basis of the China Experimental Fast Reactor (CEFR) [23]. It is the sodium-cooled reactor in the fourthgeneration nuclear power technology, neutron breeder reactor. The output power of the reactor is $600 \mathrm{MWe}$, and the designed target thermal efficiency is $40 \%$.

The China Lead-based Research Reactor [24] is researched and developed by the Institute of Nuclear Energy Safety Technology (INEST), Chinese Academy of Sciences. The design has two operating modes: the first is the critical operating mode for heavy liquid metal fast reactor technology tests, and the other is for ADS Subcritical operating mode driven by the system's accelerator.

The CSR1000 is designed and developed by the Nuclear Power Institute of China (NPIC) for supercritical water reactors in China [25]. The supercritical water-cooled reactor nuclear energy system combines advanced nuclear reactor technology and the latest supercritical fossil boiler technology, and its power station efficiency can reach $50 \%$. The operating temperature of SCWR is higher than the thermodynamic critical point of water, which has both technical advantages and challenges. Technically, supercritical water-cooled reactors can learn from the design, construction, and operation experience of existing pressurized water reactors and supercritical thermal power plants, and there are no insurmountable technical obstacles. But commercial operation will not be realized until 2030.

China's thorium-based molten salt reactor project is undertaken by the Shanghai Institute of Applied Physics of the Chinese Academy of Sciences. Its strategic goal is determining the development of the fourth-generation fission reactor nuclear energy system, focusing on solving key technical issues such as the preparation of thorium-uranium nuclear fuel, molten salt reactors, and thorium-based molten salt reactor fuel (waste) postprocessing. Through research work, it is expected that an industrial demonstration TMSR will be developed to realize the effective use of thorium resources and the full use of nuclear energy.

Therefore, if the fourth-generation nuclear energy systems shown in Table 4 can be used, utilities have a range of domestic technology options for repowering that can match with the operating steam conditions of their existing coal power plants. It can be seen from the above table that the steam parameters of the fourth-generation reactor are close to those of thermal power plants. This is due to the choice of the reactor's main coolant. Compared with water, these coolants have more stable physical properties and play a vital role in the safety of equipment operation. In this way, extensive modifications to the equipment can be avoided.

In this study, we chose China's HTR-PM reactor type for retrofit decarbonization of coal power plants [26]. The High Temperature Reactor-Pebble Bed Module (HTR-PM) is a 250 MWth small modular reactor unit cooled by helium gas, primarily developed by the INET Department of Tsinghua University. The first power plant utilizing HTR-PM units, owned and operated by the utility CHNG, is currently in commissioning at Shidao Bay in Shandong province. The HTR-PM generator unit represents the most mature and promising technology alternative to coal retrofit decarbonization. In the preliminary case study of Polish coal retrofit decarbonization, it was shown that the HTR-PM can be costeffectively integrated into existing Polish coal installations. A technical case study analysis will be carried out on the repowering of HTR-PM units of coal units in coastal cities in China in follow-up work to this study. That work will include analysis as follows:

1. Replace the coal-fired boiler with one or more HTR-PM steam generators to model the heat balance of the existing coal-fired steam cycle. This will determine what changes need to be made to the existing steam cycle and related costs.

2. Assessment of the possibilities to establish the HTR-PM construction site on the site of the coal unit, and whether the coal unit can remain in operation during construction. 


\subsection{The HTR-PM Reactor Unit as a Coal Repowering Heat Source}

The high-temperature gas-cooled reactor-pebble-bed module (HTR-PM) is a $250 \mathrm{MWth}$ small modular high-temperature gas-cooled reactor (HTGR) demonstration power plant designed by the Institute of Nuclear and New Energy Technology (INET) of Tsinghua University. Scholars at Tsinghua University have conducted research on high-temperature gas-cooled reactors since the 1970s, inspired by the German HTR-module and the American MHTGR, and completed the experimental construction of the HTR-10 in 2000 [22]. At the end of 2002, it achieved full power operation. On this basis, the first HTR-PM nuclear power plant built in Shidao Bay, Shandong Province, China has entered the final stage of construction. The goal is to reach commercial operation by Q1 2022. HTR-PM nuclear power plant is a dual-reactor structure, using two reactors connected to one steam turbine (500 MWth, $210 \mathrm{MWe),} \mathrm{which} \mathrm{is} \mathrm{different} \mathrm{from} \mathrm{all} \mathrm{types} \mathrm{of} \mathrm{nuclear} \mathrm{power} \mathrm{plants} \mathrm{currently}$ in operation. From a technical maturity viewpoint, the HTR-PM generator set represents the world's most promising alternative for coal power retrofit decarbonization.

Figure A3 (see Appendix A) shows a cross-sectional view of a single HTR-PM reactor [27]. The reactor and steam generator are in two separate pressure vessels. The primary pressure boundary also includes hot gas pipeline pressure vessels, and these facilities are installed in concrete buildings. The main helium fan is installed on the top of the steam generator. The primary helium coolant temperature at the inlet of the core is $250{ }^{\circ} \mathrm{C}$, the pressure is $7 \mathrm{MPa}$, and the outlet temperature is $750{ }^{\circ} \mathrm{C}$. The blower transfers heat to the steam generator to drive the steam turbine to generate electricity. In the steam generator, the main steam pressure is $13.25 \mathrm{MPa}$, and it is heated to produce steam at about $570{ }^{\circ} \mathrm{C}$. However, such environmental pressure is not suitable for supercritical systems. Zhang et al. redesigned the steam generator [28] and designed a supercritical steam generator with spiral coils, which can work under supercritical pressure and with a live steam temperature of $600{ }^{\circ} \mathrm{C}$. The improved steam generator design has a higher live steam temperature and reheat, further expanding the repower capability to more types of coal plants. A preliminary case study of coal retrofit decarbonization in Polish shows that [20], HTR-PM units can be economically and efficiently integrated into a typical Polish coal plant.

From the perspective of floor space, according to Ref. [26], a commercial HTR-PM power plant (HTR-PM600) uses 6 HTR-PM modules, that is, 12 reactors. One reactor building accommodates 2 reactors, and there are 6 nuclear island buildings in total. As shown in Figure 7, the direct area of the two HTR-PM600 module power plants is about $230 \times 200 \mathrm{~m}$ (46,000 square meters), which includes fuel processing facilities and electrical buildings. Therefore, according to the site schematic diagram, an HTR-PM600 factory covers an area of approximately $230 \times 100 \mathrm{~m}$ (23,000 square meters). In addition, if each reactor building encapsulates 6 units instead of 2, the size of the HTR-PM standardized building can be reduced by $50 \%$ [29].

\subsection{Licensing Aspects}

There are two main challenges in the retrofit decarbonization of nuclear reactors in existing coal power plants in China:

1. Environmental issues: whether the retrofit decarbonization plan has the possibility of ob-

taining the construction and operation permits of relevant nuclear regulatory agencies.

2. Social license: the general acceptance of nuclear energy facilities from local communities.

Environmental issues are the primary issue facing the construction of nuclear power plants. In China, nuclear power plant construction projects are generally national key projects [30]. Projects must be included in the national plan, and the country will plan and establish a project in a unified manner. It is assumed that the feasibility study report of the planned project is approved by the regulatory agency, and the main issue that determines the retrofit decarbonization is the rules of the site emergency plan. An emergency planning area is an area established in advance around a nuclear facility, where emergency plans have been formulated and emergency preparedness has been prepared. The current nuclear regulatory principles are based on large conventional light water reactors, including 
emergency planning areas of different scales. The emergency planning area of Chinese nuclear power plants is centered on nuclear power plants [31], which is divided into plume emergency planning zone (PEPZ) and ingestion emergency planning zone (IEPZ). The PEPZ is within a radius of $7-10 \mathrm{~km}$, and the IEPZ is within a radius of $30-50 \mathrm{~km}$. Taking the Qinshan Nuclear Power Plant as an example, the zone [32] delineated by the nuclear island of the nuclear power plant with a radius of $8 \mathrm{~km}$ is the PEPZ; the zone delineated by the $30 \mathrm{~km}$ radius is the IEPZ. PEPZ can be divided into an inner zone and an outer zone. The emergency protective measures implemented include evacuation plans, stable iodine intake, food and drinking water control, etc. The main protective measures within the IEPZ are food and drinking water control. In the event of a nuclear accident, radiation will begin to spread out from the inner zone of the PEPZ, and spread out under the influence of wind.

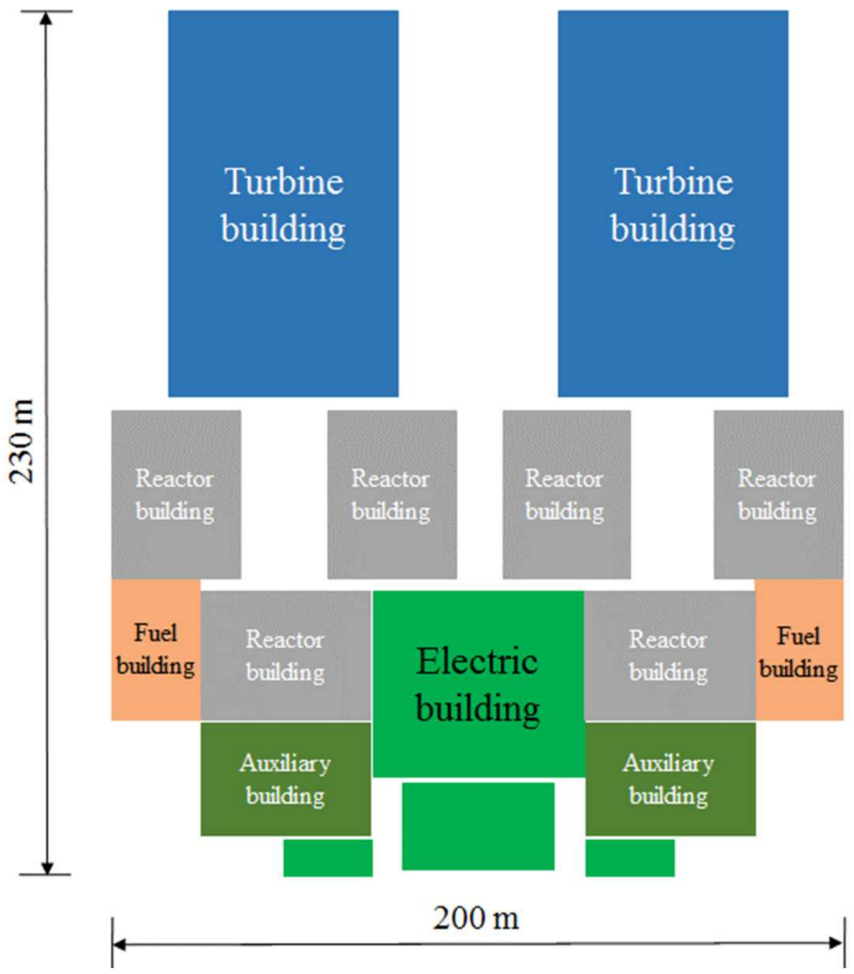

Figure 7. The $2 \times 600$ MWe HTR-PM multi-modules plant.

No modern small modular reactor (SMR) is in operation in China yet, but one has been licensed and approved for construction. The Linglong-1 (ACP100) SMR developed by China National Nuclear Corporation [32] passed the IAEA audit in 2016. In 2019 [33], China's National Nuclear Safety Administration (NNSA) conducted a technical review of the Hainan Changjiang Multi-purpose Modular Small Reactor Technology Demonstration Project Site Safety Analysis Report submitted by Hainan Nuclear Power Co., Ltd., (Changjiang, China) and approved construction. However, the corresponding rules and regulations must be followed. Once an accident occurs, it must be reported to NNSA. Such documents also indicate that the application of SMR to the retrofit decarbonization of coal power plants provides the qualifications for regulatory licenses.

While solving the environmental problems of nuclear power plants, it is also necessary to ensure a social license of the local public and political groups, and get the support of people and society. Before the Fukushima nuclear accident, the Institute of Nuclear Energy and New Energy Technology of Tsinghua University conducted five consecutive years of investigations [34] on the acceptance of nuclear energy by the domestic public from 2002 to 2006. The survey results showed that the public was aware of nuclear energy issues. The degree is relatively low, $76.3 \%$ of the respondents "just heard about nuclear energy, but did 
not know much about it" or "very little". About 71\% of people think that my country's nuclear energy science knowledge is "little" or "relatively little". Regarding the attitude toward nuclear energy development, $80 \%$ of the public are currently very supportive of the country's development of nuclear energy, but most of the public's support rate for the development of nuclear energy locally is below $50 \%$.

After the Fukushima nuclear accident, in 2018, Liu [35] conducted an investigation on the attitudes of residents around the Ningde Nuclear Power Plant. Based on the results of the investigation, they were divided into four categories: opposition, reluctant acceptance, support, and irrelevant. Those interviewees who were opposed were middle-aged people over 40 years old with low level of education. They were basically engaged in a single production activity and had no other employment skills. Respondents with an attitude of reluctant acceptance are mostly young people with a high school degree or above, who are in their 20s to 30s, and have a certain sense of belonging to their hometown. These people believe that there are certain risks in nuclear power plants, and their own risks and interests are not balanced. If they are allowed to make a choice, they will oppose the construction of nuclear power plants locally, but because it is a national project, in reality they will remain silent and acquiesce in the project process. Respondents who support it are because nuclear power brings economic benefits. Interviewees who do not care have limited knowledge and awareness of nuclear risks, and they are therefore not concerned about the possible environmental impact of nuclear power plants.

\subsection{General Site Requirements}

The site selection planning of nuclear power plants should comply with national and local regulations on urban planning and construction, and be coordinated with local urban planning. This is similar to coal power plants. To a certain extent, the two have overlaps, which makes it technically feasible to repower coal with nuclear power. For nuclear power plants, from a safety and technical point of view, stricter regulations need to be followed [36], such as:

1. The population distribution requires urban planning to meet the population density and central city conditions. The aim is to site as close as possible to the load center and as far away as possible from the concentrated residential area.

2. Prevent external man-made hazards near the site, which means avoiding siting near large hazardous facilities such as chemicals, explosives production plants and storage warehouses, oil refineries, oil and natural gas storage facilities, and pipelines that transport flammable gases or other dangerous substances. In addition, we need to pay attention to the civil airports, military airports, and air routes near the site.

3. Site away from areas with a high frequency of natural disasters, including floods, tsunamis, mudslides, or extreme natural disasters.

In the site selection, a detailed investigation must be carried out on the conditions of the foundation rock mass to determine the load-bearing capacity. Because whether it is a coal power plant or a nuclear power plant, its equipment imposes a very heavy load on the subsoil, and it is necessary to strengthen the design of the foundation to ensure its load-bearing capacity. For nuclear power retrofit decarbonization, it may be necessary to rebuild and strengthen part of the subsoil of the original site to determine the strength and other physical characteristics of the on-site stratum.

In addition, in the site-selection process, it is necessary to determine whether the site can meet the transportation requirements of the nuclear power plant. There are mainly two parts: One is the transportation method of overweight and oversized parts; the other is the storage and transportation of nuclear fuel, spent fuel, and solid waste. For the former, the method that is generally suitable for the original coal power plant is also suitable for the transportation of nuclear power equipment. If the transportation conditions cannot be met, the site needs to be changed. In this regard, the advantages of power station near the coast are highlighted, and existing docks can be used for the transportation of overweight and oversize parts. For the latter, this is unique to nuclear power plants. Nuclear fuel can be 
transported by a combination of rail, road, and sea with no major difficulties. However, because of its radioactivity, spent fuel must be transported with special containers and safety measures to ensure transportation safety and avoid radioactive pollution.

\subsection{Seismic Conditions}

In addition to ensuring the safety of the power plant by means of redundancy and isolation in terms of system and overall design, nuclear power plants must also ensure that they can safely withstand a certain degree of earthquake. The International Atomic Energy Agency (IAEA) has a series of safety guidelines and design safety requirements for site selection and design of nuclear power plants. Based on the relevant IAEA guidelines and requirements, China has compiled a code for seismic design of nuclear power plants suitable for China based on actual conditions. When evaluating seismic conditions, there are several requirements that need to be noted:

1. The site must be investigated for ground movement, surface fractures, waves caused by earthquakes and earthquake-related permanent ground deformation phenomena and related geological phenomena. Through geological exploration and historical records, the developer determines the seismic standards of the power plant design.

2. The size of the survey area, the type of data collected, and the scope and detail of the survey must be determined according to the characteristics and complexity of the seismic tectonic environment, so that engineering design benchmarks can be established.

3. The degree of seismic hazard is related to the determination of the design basis ground motion. It must be based on the seismic structure model. It is recommended to adopt more stringent motion parameters as safety standards, such as seismic intensity, ground acceleration, vibration duration, and time history curve.

China has a vast land area, a long coastline, and is located between the Pacific Rim seismic belt and the Eurasian seismic belt. The geological conditions of each proposed site must be investigated in detail, not only to reduce the impact of the earthquake on the nuclear power plant from the outside, but also to strictly require it to withstand a certain magnitude of the earthquake during the construction of the nuclear power plant.

\subsection{Establishing Construction Sites}

As part of the construction project, different buildings and auxiliary facilities must be planned. Usually there are many different teams and suppliers on the construction site for collaborative work in different areas. Generally speaking, the temporary construction areas of coal power plants are placed in coal storage areas, which indicates that new nuclear reactor construction sites can also be established in these areas. When transforming some large coal-fired power units, the degree of modular construction will be greater, which can reduce part of the floor space required and improve construction efficiency. For example, for a $1200 \mathrm{MW}$ nuclear power plant, its building facilities include turbine buildings, auxiliary buildings, cooling systems, and switch stations. Through modular design with prefabricated modules, the construction site area can be reduced by about $25 \%$. If the existing coal plant equipment and buildings are fully utilized, the construction site area may be further reduced by $25 \%$. If the original construction area per unit power is $650 \mathrm{~m}^{2} / \mathrm{MW}$, through nuclear retrofit decarbonization construction, it has become $325 \mathrm{~m}^{2} / \mathrm{MW}$, which greatly improves the land utilization rate.

\subsection{Reactor and Coal Unit Pairing}

In the retrofit process, we need to study the matching situation between the reactor and the original equipment of the coal power plant, and analyze the possibility of different types of coal power units in detail. The method of pairing and integration research mainly satisfies two requirements:

1. Based on the existing reactor design, no other modifications are made and the nominal heat load operation is maintained. 
2. On the premise of maximizing the use of existing assets, reduce the modification of the equipment of the conventional island and the balance of plant.

The HTR-PM unit as the object of retrofit depends on China's current mature experience in the reactor research. Analysis of the selection of modular reactors used in decarbonization representative coal power plants for the three types of coal power units: small units, medium units, and large units. For example, two HTR-PM units (500 MWth nominal) could be coupled to a $750 \mathrm{MWth}$ or $1000 \mathrm{MWth}$ rated thermal power existing coal unit steam cycle. The detailed mathematical model of coal-fired units is used to simulate nuclear retrofit power plants and find a successful way to integrate the heat output of nuclear reactors with the existing steam cycle.

\subsection{Licensing Experience with Smaller Emergency Planning Zones}

As part of the defense-in-depth measures, each country has made the classification for the types and sizes of emergency planning areas [37].

However, for an advanced small modular reactor, the emergency zone requirements are expected to be reduced substantially. The main SMR technology studied in this paper is the HTR-PM. In China, Ding et al. [37] conducted a special emergency planning zone study on HTR-PM. First, the emergency plan reference accident sequence is determined for this type of reactor, and then the possible source items are estimated for these emergency plan reference accident sequences, and the weather sequence, dispersion model, and dose assessment method are used to evaluate the radiological consequences and pollution level. Finally, by comparing with the dose criteria, a reasonable EPZ size was formulated from a technical point of view. The results show that HTR-PM will not affect the zone outside the nuclear power plant site, which means that an emergency planning zone with a nuclear island as the center and a radius of $500 \mathrm{~m}$ is sufficient to cover emergency response needs. Therefore, in view of such research, we can reasonably assume that on the basis of existing coal power plants, even some power stations in densely populated areas can be repowered with small modular reactors.

\subsection{Seismic Analysis and Activity in China}

China has a large land territory located between the two major seismic belts, the Pacific Rim Seismic Belt and the Eurasian Seismic Belt, which leads to very active movement of the seismic fault zone. According to the division of the Institute of Geophysics of the Chinese Academy of Sciences, China has 23 seismic zones that span the entire Chinese territory. Due to the differences in tectonic activity in various regions, the length of the seismic activity period is different. The period of seismic activity in eastern China is generally longer than that in the west, with a period of about 300 years in the east, 100-200 years in the west. Generally speaking, the period of seismic activity at the edge of the plate is shorter, and the period of seismic activity inside the plate is longer. In addition, earthquake repeatability refers to the repeated occurrence of earthquakes in situ. Generally speaking, the larger the earthquake, the longer the repetition time, the smaller the magnitude, the shorter the repetition time. However, due to differences in the strength of tectonic activity in different seismic regions and belts, the length of repetition time of earthquakes of the same magnitude is also different. According to statistics, the repetition time of magnitude 6 earthquakes can range from decades to hundreds of years, and the repetition time of earthquakes above magnitude 7 is more than a thousand years or even several thousand years. Figure A4 (see Appendix A) shows the number of destructive earthquakes [38] recorded in China from 1831 BC to 1969 AD, with a total of more than 5000. Therefore, it is necessary to assess the risks of local earthquakes to nuclear power plants when selecting sites for nuclear power plants.

Earthquake ground motion parameters are an important condition for nuclear power plant site selection and design. Reliable investigations of geologically active faults must be carried out. The site should be far away from active faults and should be located in areas with low seismic intensity. Even if it is to be designed on an earthquake zone, it should 
be designed to withstand what is known as the operating baseline earthquake, which the reactor building should handle with interruption to continuous operation. Generally, taking LWR as an example, the peak ground acceleration designed for its reactor site is $0.2 \mathrm{~g}$. In some areas, by adding a seismic isolation system to the site, the plant can withstand $0.3 \mathrm{~g}$. Figure A5 (see Appendix A) shows the peak ground acceleration in all areas within China.

It can be seen from the map that the PGA in coastal areas of China is generally between 0.1 and $0.2 \mathrm{~g}$, except for the PGA in Fujian in the Taiwan Strait, which is higher than $0.2 \mathrm{~g}$. As it goes further inland, the PGA of the southeastern region near the coast is lower than that of Hebei Province and Shandong Province in the North China region, and the PGA of Hebei Province and Shandong Province near the coast is between 0.1 and $0.4 \mathrm{~g}$, and even reaches $1 \mathrm{~g}$ in some areas. The inland PGA of the northeast and southern regions is less than $0.2 \mathrm{~g}$, because these two areas are mostly plains and hilly areas. Due to the mountainous nature of the inland, especially the Qinghai-Tibet region, the darker-colored regions on the map generally have a PGA greater than $0.2 \mathrm{~g}$, so this region is not suitable for the construction and retrofit of nuclear power plants. In summary, it can be seen that coastal areas are suitable for nuclear retrofit, and near coastal areas are more suitable for transformation, but local areas should be avoided, mountainous areas should be avoided in inland areas, while plain areas such as northeast and southern areas appear suitable.

Therefore, based on the above analysis and the previous estimation of the three-stage retrofit potential, it is conservatively estimated that $4 \mathrm{GW}$ of installed capacity is not suitable for retrofit in the 1st stage, and $10 \mathrm{GW}$ of installed capacity is estimated to be unsuitable for retrofit in the 2 nd stage. In the 3 rd stage, it is conservatively estimated that about $40 \mathrm{GW}$ of installed capacity is not suitable for retrofitting. The final feasible retrofit potential is shown in Table 5.

Table 5. Capacity of possible repowering in China.

\begin{tabular}{ll}
\hline Different Stages & Capacity of Possible Repowering(GW) \\
\hline 1st & 75 \\
2nd & 175 \\
3rd & 603 \\
\hline
\end{tabular}

\section{Representative Chinese Coal Power Plant Units}

In order to assess the potential and cost of nuclear retrofit decarbonization programs near coastal cities in China, this section mainly describes the steps of nuclear power retrofit decarbonization in detail. The first is an introduction to the overall coal power plant and its various components, and then a detailed description of the transformation of representative thermal power plants, including plant site layout, facility changes, etc., and finally an analysis of the cost savings brought about by the retrofit decarbonization.

\subsection{Description of a Coal Power Plant and Associated Equipment}

Figure 8 is a schematic diagram of the general overview and facility layout of a typical coal power plant.

Figure 8 is the site layout of a coal power plant. It can be found from the figure that the layout of the on-site facilities of a coal power plant mainly changes according to the installed capacity of the unit and the type of coal. Large thermal power stations need to take up a large area of land for high-voltage conversion and then be transported to various power consumption areas via transmission lines. Small thermal power stations can dispense with this part of the operation and directly transport local power consumption areas. Coal power plants consume a lot of water in terms of cooling, ash and slag cleaning, and boiler water replenishment. Coal-fired power units located near large waters usually use direct-flow cooling, which uses open cooling with river water, lake water or sea water as cooling water. Close to the inland, units without sufficient water sources generally use circulating cooling, which is used for circulating cooling by constructing cooling towers or cooling pools. The type of coal is also one of the factors that affect the site layout. Thermal 
power plants have a very large demand for fuel, and the type of fuel directly determines their site layout. For power plants whose fuel type is lignite, they are usually located near the production site and can be supplied with fuel directly from the mine for processing without occupying a large amount of land. For hard coal types, it is usually necessary to have railway or port receiving infrastructure for handover and transport to storage areas for placement and processing. In addition, a large amount of ash will be generated. These wastes are temporarily stored on site and transported to other factories for processing.

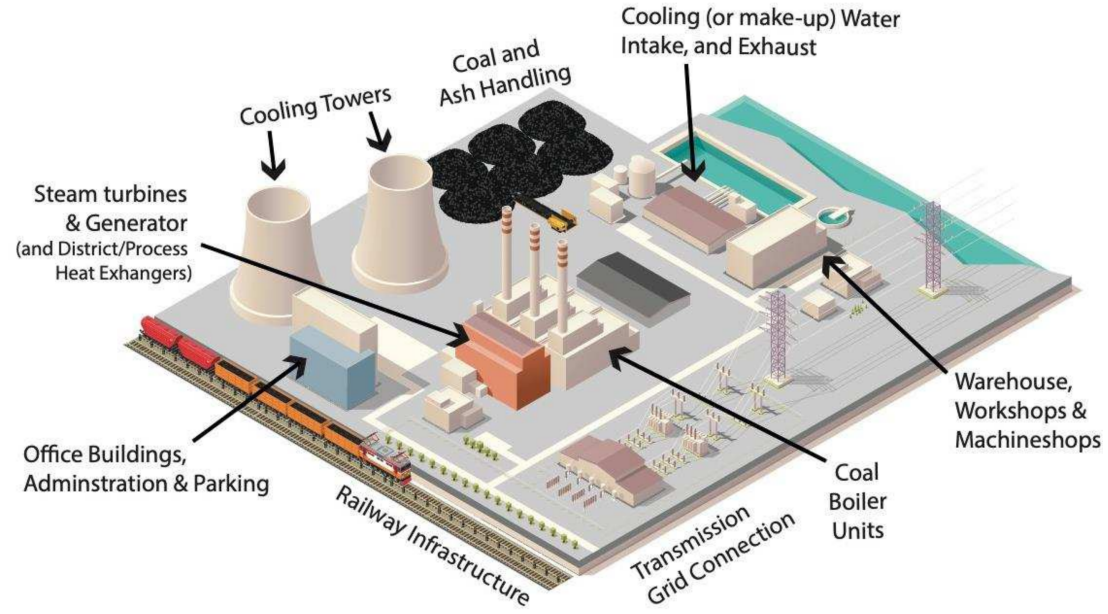

Figure 8. Coal power plant site layout and major components [20].

\subsection{Representative Chinese Coal Power Units}

The coal-fired power plants in coastal cities are classified. According to Table 3, three representative coal-fired units of small, medium, and large units are transformed and analyzed. Three types of plants are selected for retrofit instructions, and their specific locations are shown in Figure A6 (see Appendix A).

As an example of a small unit, we use the Dalian Taishan Thermal Power Station, which is a coal-fired power station located in Shahekou District, Dalian City, Liaoning Province, China. It is mainly used for power supply and heating in urban areas. The power plant has a large circulating cooling water of 8700 cubic meters per hour using cooling towers. There are two existing $135 \mathrm{MW}$ condensing steam-heated steam turbine units, which were completed and put into operation at the end of 2005. The auxiliary boiler of the power plant uses the intermediate reheat natural circulation steam drum circulating fluidization produced by the Harbin Boiler Factory imported from Germany's EVT boiler technology. The designed maximum continuous evaporation capacity is $440 \mathrm{t} / \mathrm{h}$, the outlet steam pressure is $13.7 \mathrm{MPa}$, and the outlet temperature is $540{ }^{\circ} \mathrm{C}$. The coal fuel used by the power plant is mainly lignite. In the past, the desulfurization method was to add limestone powder to the boiler, which would cause serious environmental pollution and cause environmental protection to be of substandard. The power plant covers an area of about $0.23 \mathrm{~km}^{2}$, and the land use area is $850 \mathrm{~m}^{2} / \mathrm{MW}$. The overall layout is shown in Figure 9.

As an example of medium-sized units, we use the Huaneng Yangliuqing Power Plant, located in the east of Yangliuqing Town, Xiqing District, Tianjin, in the load center of the Beijing-Tianjin-Tangshan power grid. This is a regional large-scale thermal power plant for heating, affiliated to HUANENG POWER INTERNATIONAL, INC (Beijing, China). The existing installed capacity of the whole plant is $1200 \mathrm{MW}$, made up of four $300 \mathrm{MW}$ units. The four units are all coal-fired extraction steam heating units, with a designed heating area of approximately 20 million square meters. The rebuilt two $300 \mathrm{MW}$ units are equipped with $2 \times 1025 \mathrm{t} / \mathrm{h}$ liquid slagging furnaces imported from Germany, which have high environmental performance, which can achieve only slag discharge without ash discharge, 
and avoid dust. The construction of the other two $300 \mathrm{MW}$ units in 2005 has three major characteristics: First, cogeneration, which can replace 121 scattered small boilers in the existing 70 small boiler houses in the heating area. In addition, all industrial water can be water that has been properly treated in the city; third, the environmental protection facilities are complete, and the discharge indicators will meet the national environmental protection standards. According to current information, the plant covers an area of about $1 \mathrm{~km}^{2}$, and the land use area can reach $833 \mathrm{~m}^{2} / \mathrm{MW}$. The site layout is shown in Figure 10.

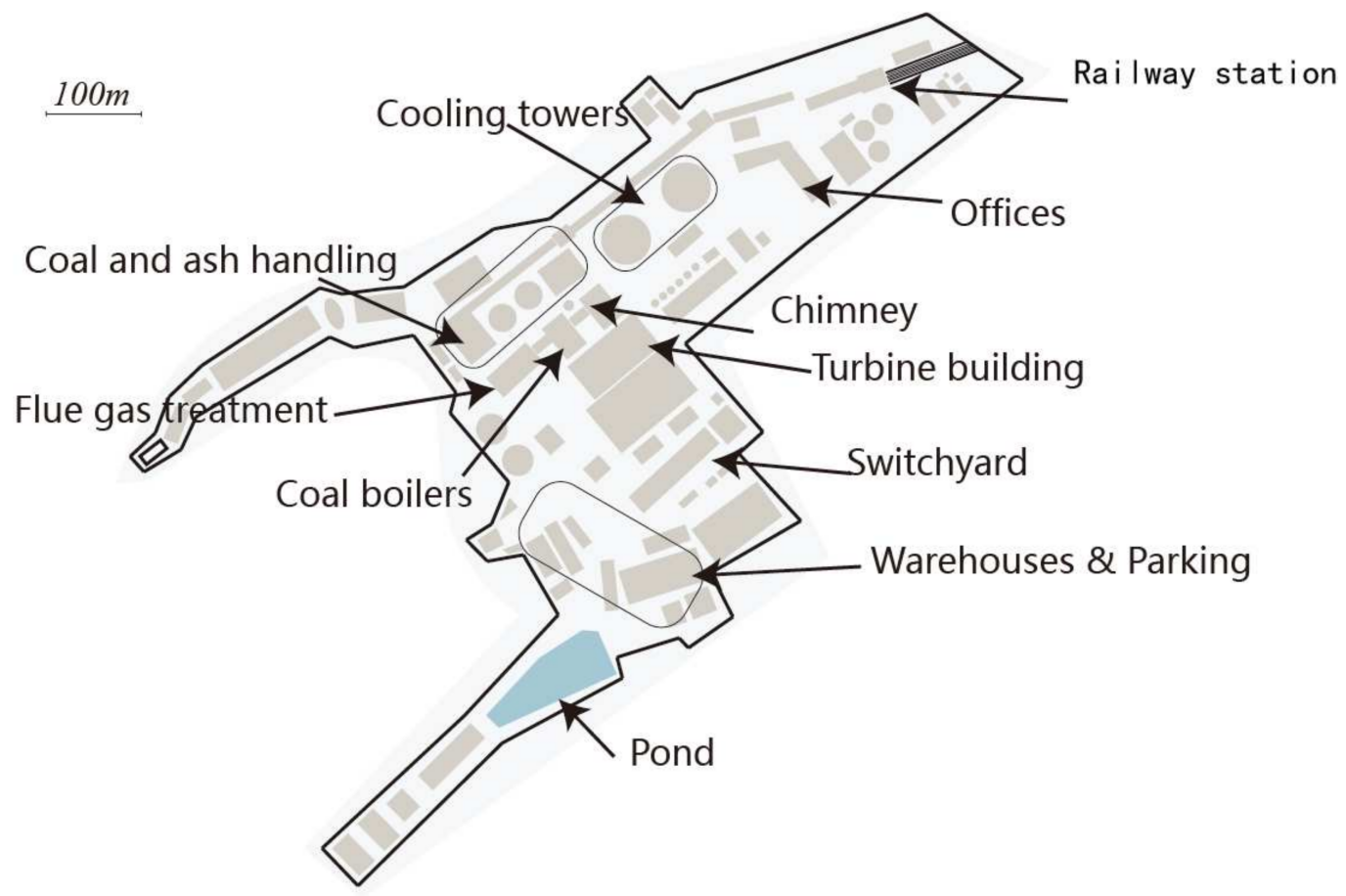

Figure 9. Dalian Taishan power station power plant site layout.

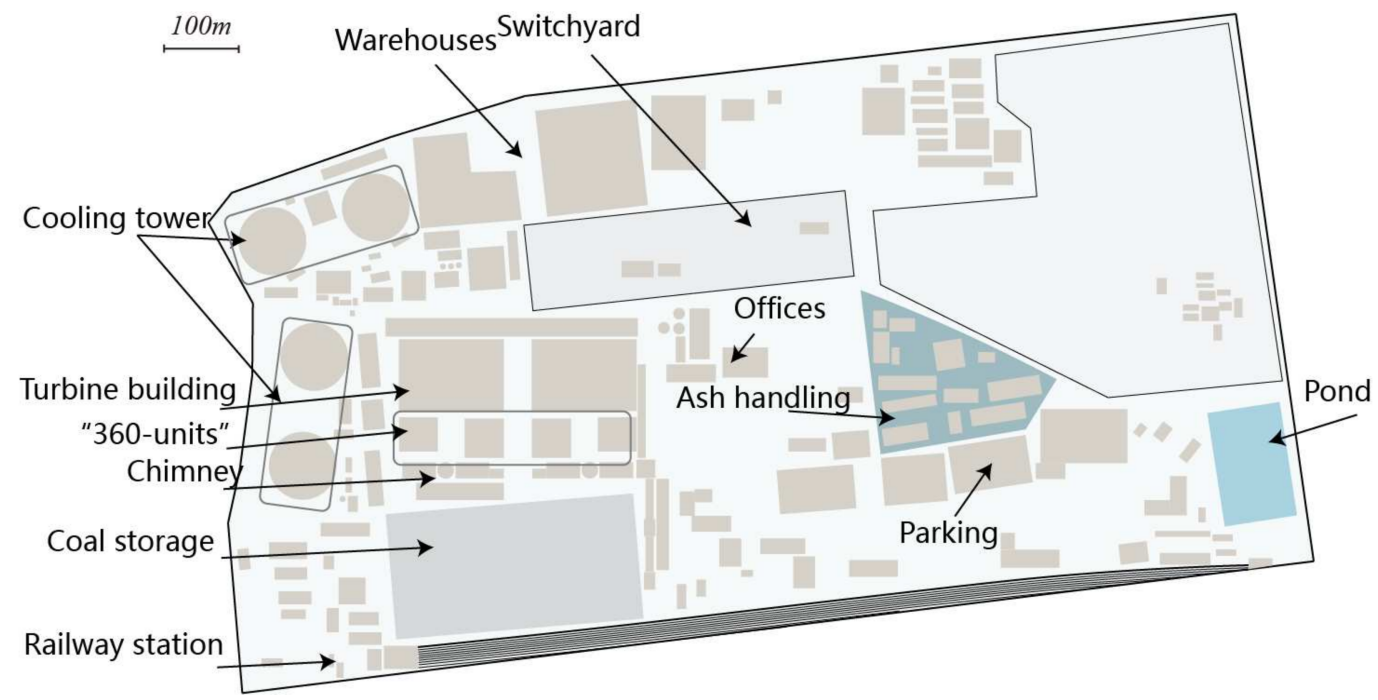

Figure 10. Huaneng Yangliuqing power station Power Plant Site Layout.

As an example of large units, we use the Zhuanghe Power Station located in Zhuanghe City, Dalian City, Liaoning Province. It is equipped with two $600 \mathrm{MW}$ supercritical coal-fired units, and high-efficiency electrostatic dust removal and flue gas full desulfurization devices. The power generation is connected to the Dalian Power Grid in southern Liaoning with two 
$500 \mathrm{kV}$ voltage level lines. The steam turbine is a supercritical, primary intermediate reheat, three-cylinder four-exhaust, single-shaft, double-back pressure, condensing, eight-stage regenerative extraction steam turbine manufactured by Harbin Turbine Co., Ltd. (Harbin, China). The model is CLN 600-24.2/566/566. This unit was designed and manufactured by Harbin Steam Turbine Factory Co., Ltd. and Mitsubishi Company. The boiler was selected from the HG-1950/25.4-YM3 600 MW supercritical once-through boiler designed and manufactured by Harbin Boiler Factory. The generator was made by Harbin Electric QFSN-600-2YHG manufactured by the factory. The main parameters of the unit are: the design power generation capacity is $600 \mathrm{MW}$, the main steam pressure is $24.2 \mathrm{MPa}$, the main steam temperature is $566^{\circ} \mathrm{C}$, and the reheat steam temperature is $566^{\circ} \mathrm{C}$. The power plant covers an area of about $1 \mathrm{~km}^{2}$, and the land use area is $830 \mathrm{~m}^{2} / \mathrm{MW}$. The overall layout is shown in Figure 11.

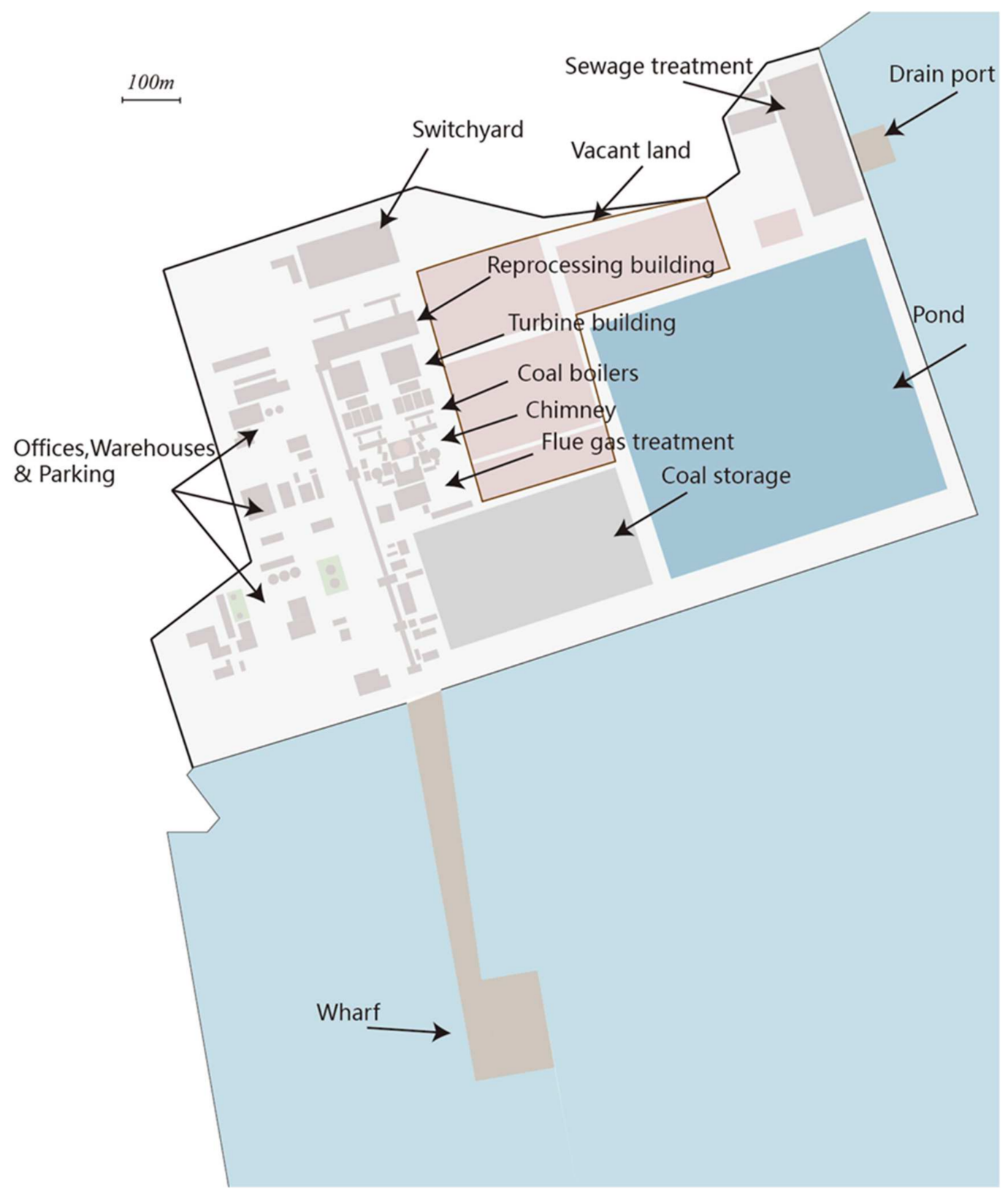

Figure 11. DALIAN Zhuanghe power plant site layout. 


\subsection{Establishing Construction Sites}

It appears technically feasible to couple a nuclear island part and related buildings to an existing coal power plant, but it may be challenging to find available space for construction. Generally, coal storage areas can be selected for construction site of nuclear reactors. For large nuclear power plants, after the project is contracted to the construction party, it is necessary to provide at least $0.3 \mathrm{~km}^{2}$ to the contractor for construction operations and storage areas [39], which includes the temporary placement of facilities and the temporary storage of earthwork for excavation construction. At present, the Ningde Fuqing Nuclear Power Plant has four 1000 MWe pressurized water reactor nuclear power units, with a total area of about $2.53 \mathrm{~km}^{2}$, and a construction site of about $1.38 \mathrm{~km}^{2}$, or about $345 \mathrm{~m}^{2} / \mathrm{MW}$. The total installed capacity of Qinshan Nuclear Power Station is $6564 \mathrm{MW}$, and the construction site area is about $2.14 \mathrm{~km}^{2}$, or about $326 \mathrm{~m}^{2} / \mathrm{MW}$. These two nuclear power plants are typical pressurized water reactors. Transition to more modularity in design and using the existing equipment and building facilities at the same time, it can be assumed that the original floor space will be reduced $25 \%$.

To illustrate the potential for establishing nuclear reactor construction sites at existing Chinese coal plants, the representative coal-fired power plants (Taishan, Yangliuqing and Zhuanghe) were used as a case study, as shown in Figures A7-A9 (see Appendix A).

Figure A7 (see Appendix A) shows a small unit retrofit drawing using 2 HTR-PM modules. The boiler and other areas were demolished and rebuilt into temporary construction areas on the original site, and the cost of retrofitting and reactor facilities were attached to the steam turbine site. Figure A8 (see Appendix A) shows a medium unit retrofit diagram using 2 HTR-PM600 modules. There are four boilers on the original site, and each boiler is connected to a steam turbine. In the renovation of all facilities on the site, three HTR-PM modules are used to connect a steam turbine, with a total area of approximately 50,000 square meters. Figure A9 (see Appendix A) is a site retrofit diagram of two large 600 MW supercritical units. Two HTR-PM600 modules are also used, and each steam turbine is connected to 12 HTR-PM module reactors. During the construction process, in order to ensure the safety of the construction and the progress of the project, the coal power is assumed to be shut down. More research is needed to assess whether the coal units could be kept in operation during the construction of the replacement heat source.

\subsection{Coal Plant Job Retention}

The number of personnel in a coal power plant is closely related to the type, scale, number of units, tasks, degree of automation, overall layout of the power plant, and regional conditions. Generally speaking, referring to the "Standards for Labor Quota for Thermal Power Generation" issued by China in 1998, there are mainly three types of personnel: management personnel, operating personnel, and maintenance personnel. According to the capacity level of the unit, the average number of personnel required per GW unit is about 300-500. IAEA has done a special study on SMR [40], and evaluated the annual scale of various SMR personnel, with the purpose of optimizing staffing and improving factory economy. The surveyed data show that the unit capacity is 500-1300 MWth, and the number of personnel has increased from 350 to 750 . In some respect, the staffing requirements of nuclear power plants and coal power plants have common aspects. For example, most of the work is standard non-nuclear maintenance, operation, and scale work. Therefore, after the factory is renovated, the employees employed by the original factory can be retained, assuming that $2 / 3$ jobs of the original factory are retained. In addition, expertise related to the nuclear field needs to be added separately.

\section{Conclusions and Discussion}

In this study, we suggest a three-stage retrofit route that replaces existing coal power plant boilers with high-temperature nuclear heat sources based on China's unique national conditions. In the 1st phase, about $80 \mathrm{GW}$ of total installed capacity can be used for retrofit decarbonization. These coal power generating units are located on the coast in areas that 
already have nuclear power plants. In the 2 nd phase, there is about $180 \mathrm{GW}$ of retrofit potential, and these units are located inland in the coastal provinces of China. These provinces have a greater demand for electricity than inland provinces, and the feasibility of transformation is also higher. In the 3rd phase, the remaining units located in the inland areas will be retrofitted, with a total installed capacity of nearly $640 \mathrm{GW}$. In the retrofit decarbonization of nuclear power plant, in order to minimize stranded assets, advanced high-temperature small modular reactors are used to replace the original coal-fired boilers. According to literature [27], HTR-PM module is used as a replacement. The construction of the greenfield nuclear power plant can be reduced by about $1 / 3$ when used to repower an existing modern coal plant. Assuming that the cost of a greenfield HTR-PM-based nuclear power plant is $3000 \$ / \mathrm{kW}$, in China, HTR-PM retrofitting costs can save $1000 \$ / \mathrm{kW}$. If a third of the total repowering potential is realized, the retrofit decarbonization of $300 \mathrm{GW}$ can save nearly $\$ 300$ billion in upfront costs compared to a greenfield expansion of the same scale. It can not only solve the losses caused by stranded assets, streamline the siting process, and avoid local job losses, but also reduce financial risks of the low-carbon transition.

The high proportion of coal power in the structure of China's power system is the result of a balance between policy, technology, and economy. With the achievement of the goal of carbon neutrality, China is committed to exploring new technologies to replace traditional coal-fired power. Nuclear retrofit decarbonization of coal power plants should be added to the menu of options available to policy-makers and utilities.

According to the two goals of global temperature rise control at $1.5{ }^{\circ} \mathrm{C}$ and $2{ }^{\circ} \mathrm{C}$, Pfeiffer [41] systematically assessed the technical, economic, and environmental impacts of coal power plants currently in operation in China, and formulated a corresponding decommissioning schedule. If we look at the problem from the perspective of resource efficiency and under the premise of achieving the goal of carbon neutrality, decommissioning and dismantling all the equipment at existing coal power plants may not the best choice. Through nuclear repowering, much of this equipment can remain in use.

In order to explore the maximum retrofit decarbonization potential, this article includes all retrofitable plants into the scope of retrofitting. That does not mean that the conversion of all coal power plants into nuclear plants is the optimal or most realistic approach. There will definitely be some power plants transformed into natural gas-combined cycle, open-cycle gas turbines, and other types of power plants, because the realizable potential for retrofit of nuclear power plants may be limited by other factors such as local public acceptance.

The research objectives of this project are meant to help facilitate decarbonization of the Chinese power system, for example, by reducing costs, increasing acceptance, and addressing obstacles such as stranded assets in existing infrastructure. Finally, the following two conclusions can be presented:

1. This research provides the technical and economic basis for the retrofit decarbonization of nuclear SMR (especially HTR-PM) power plants for major public utilities in China that are currently operating and constructing coal-fired power plants. Using real plant data to carry out on-site transformation and demonstration of representative plant units to ensure the validity and reliability of the data has played an important role in the decarbonization of China's nuclear transformation.

2. This research provides validated input data to solve the blank area of China's domestic thermal power retrofit decarbonization. The use of HTR-PM modules for retrofit can save up to $\$ 1200$ billion, which solves the problem of stranded assets and brings great economic benefits to the society.

Author Contributions: Conceptualization, S.X.; formal analysis, S.X.; funding acquisition, Y.Z. and S.Q.; methodology, S.X., Y.Z. and S.Q.; investigation, S.X., Y.H.M.L., M.M., Y.Z. and K.Y.; writingoriginal draft preparation, S.X.; validation, Y.Z. and S.Q.; writing-review and editing, S.X., Y.H.M.L., M.M., K.Y., Y.Z. and S.Q. All authors have read and agreed to the published version of the manuscript.

Funding: This research was funded by the Quadrature Climate Foundation, grant number 12-20-000071. 
Institutional Review Board Statement: Not applicable.

Informed Consent Statement: Not applicable.

Data Availability Statement: Data presented in this study relating to the status of China coal units are available in summarized form on request from the corresponding author. Data are not publicly available due to its proprietary nature. Other data presented in this study are available on request from the corresponding author.

Acknowledgments: Acknowledgement for the data support from "China Earthquake Networks Center, National Earthquake Data Center. (http:/ / data.earthquake.cn)". (accessed on 10 November 2021).

Conflicts of Interest: The authors declare no conflict of interest. The funders had no role in the design of the study; in the collection, analyses, or interpretation of data; or in the writing of the manuscript. The funder supported the decision to publish the results.

\section{Appendix A}

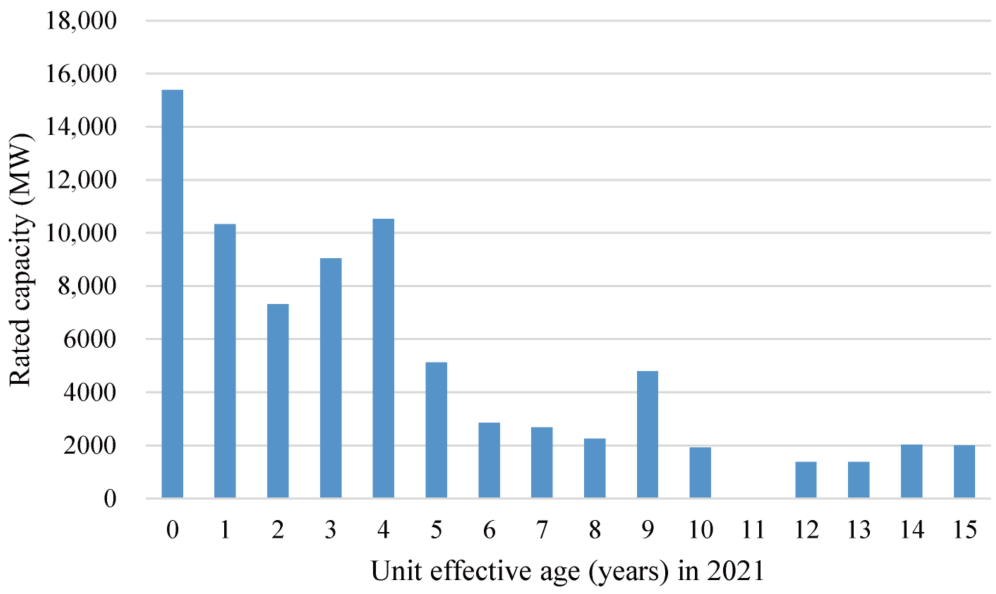

Figure A1. Capacity age-distribution of first-stage coal units (in the year 2021).

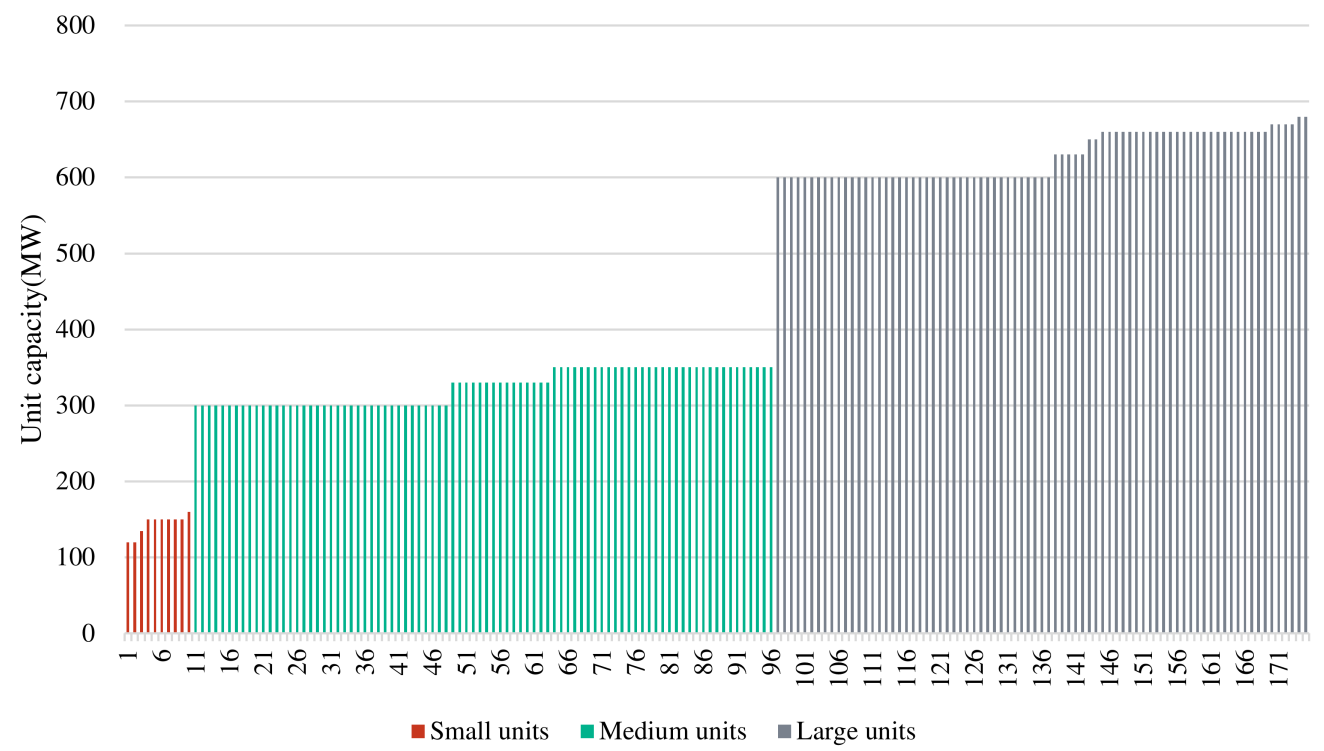

Figure A2. Classification of coal power generating units in coastal cities in China. 


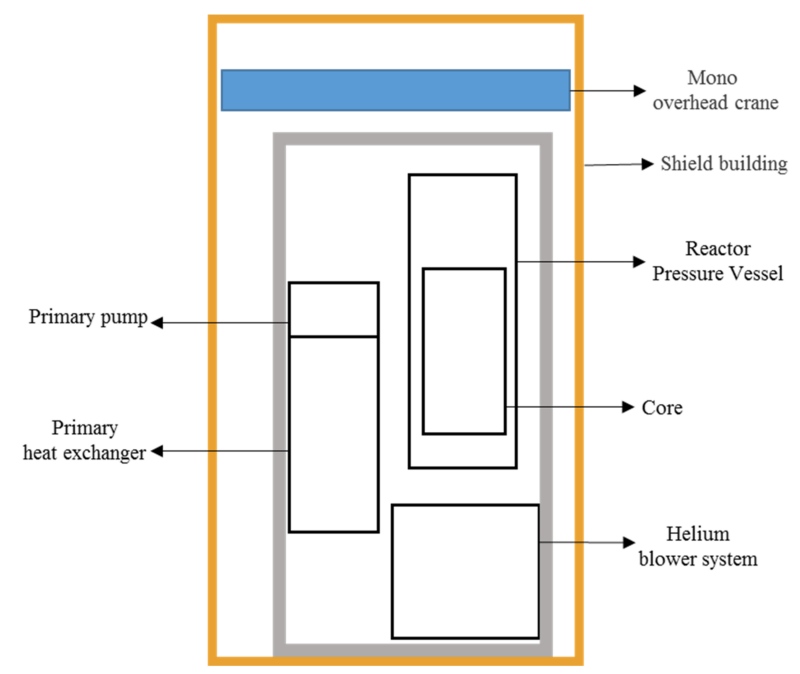

Figure A3. Cross-section of the HTR-PM reactor building [27].

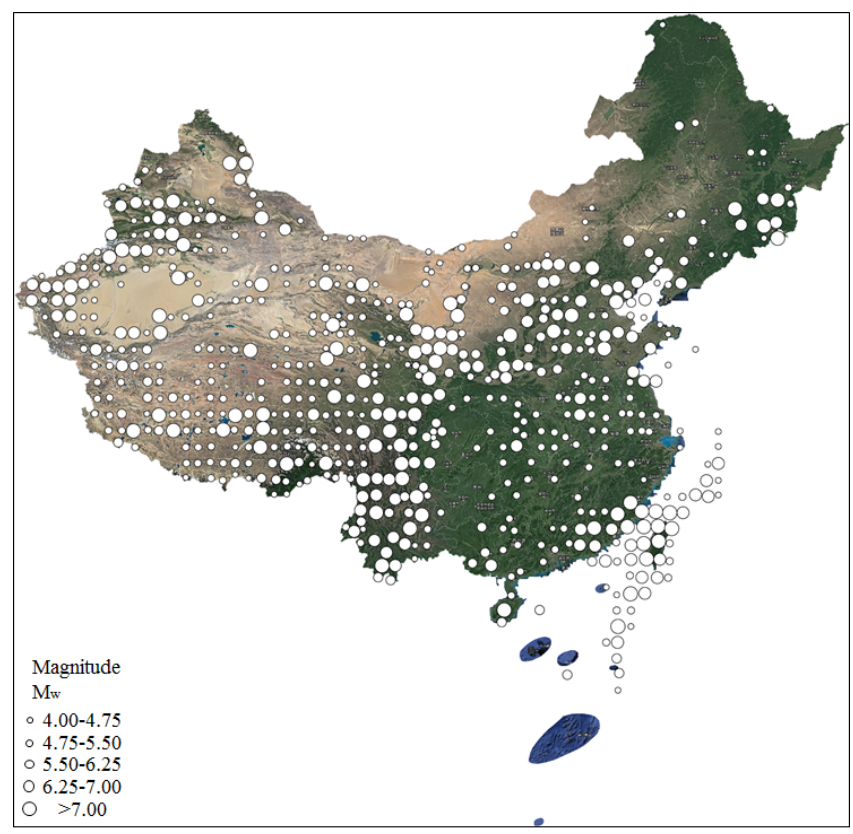

Figure A4. Earthquakes in China, year 1831 BC to 1969 AD (developed from Ref. [38]).

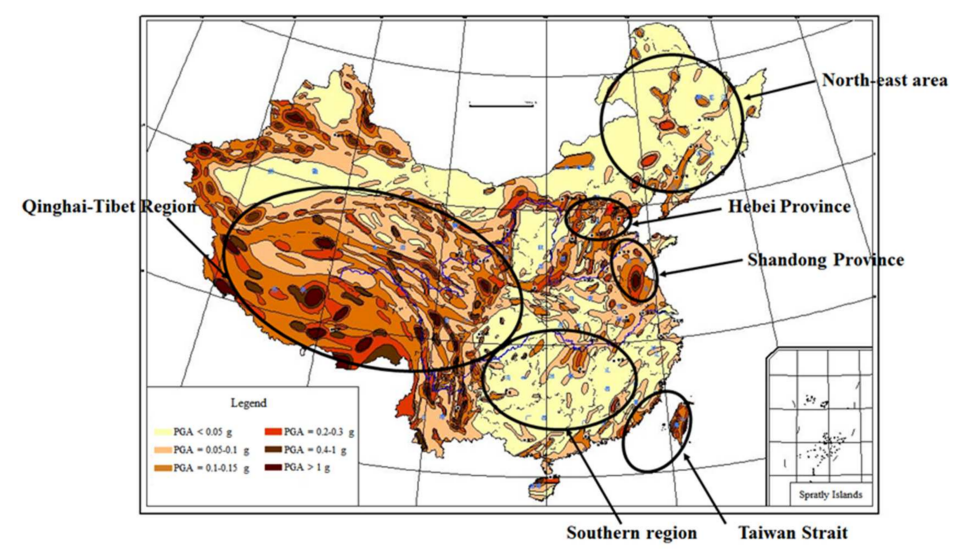

Figure A5. China peak ground acceleration map [38]. 


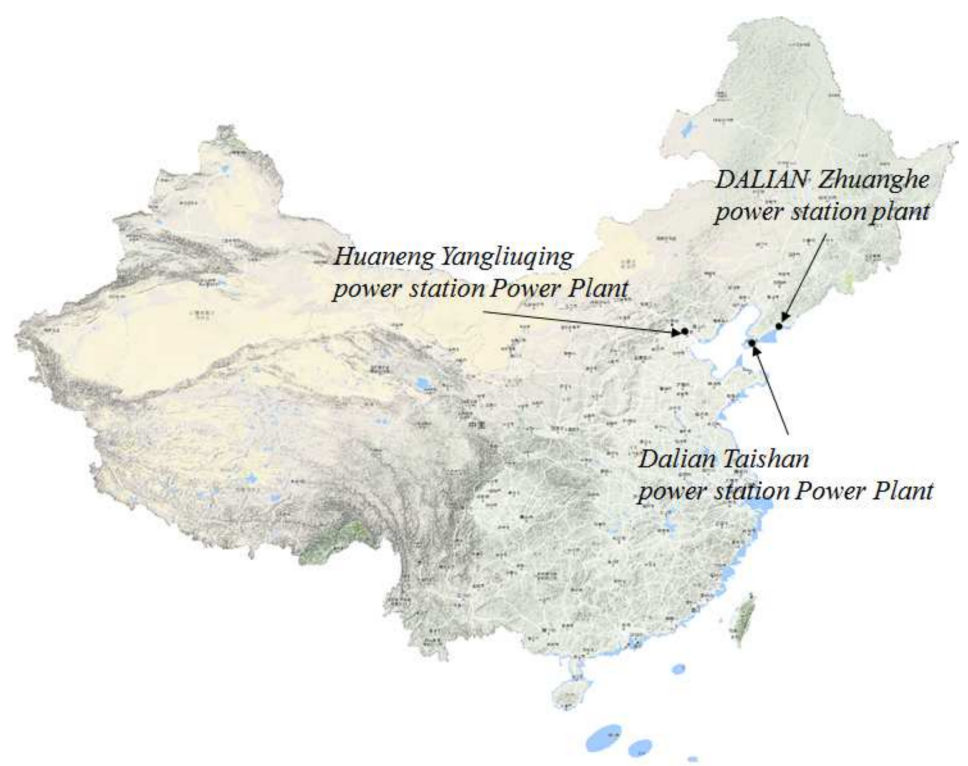

Figure A6. A map of three plants in China.

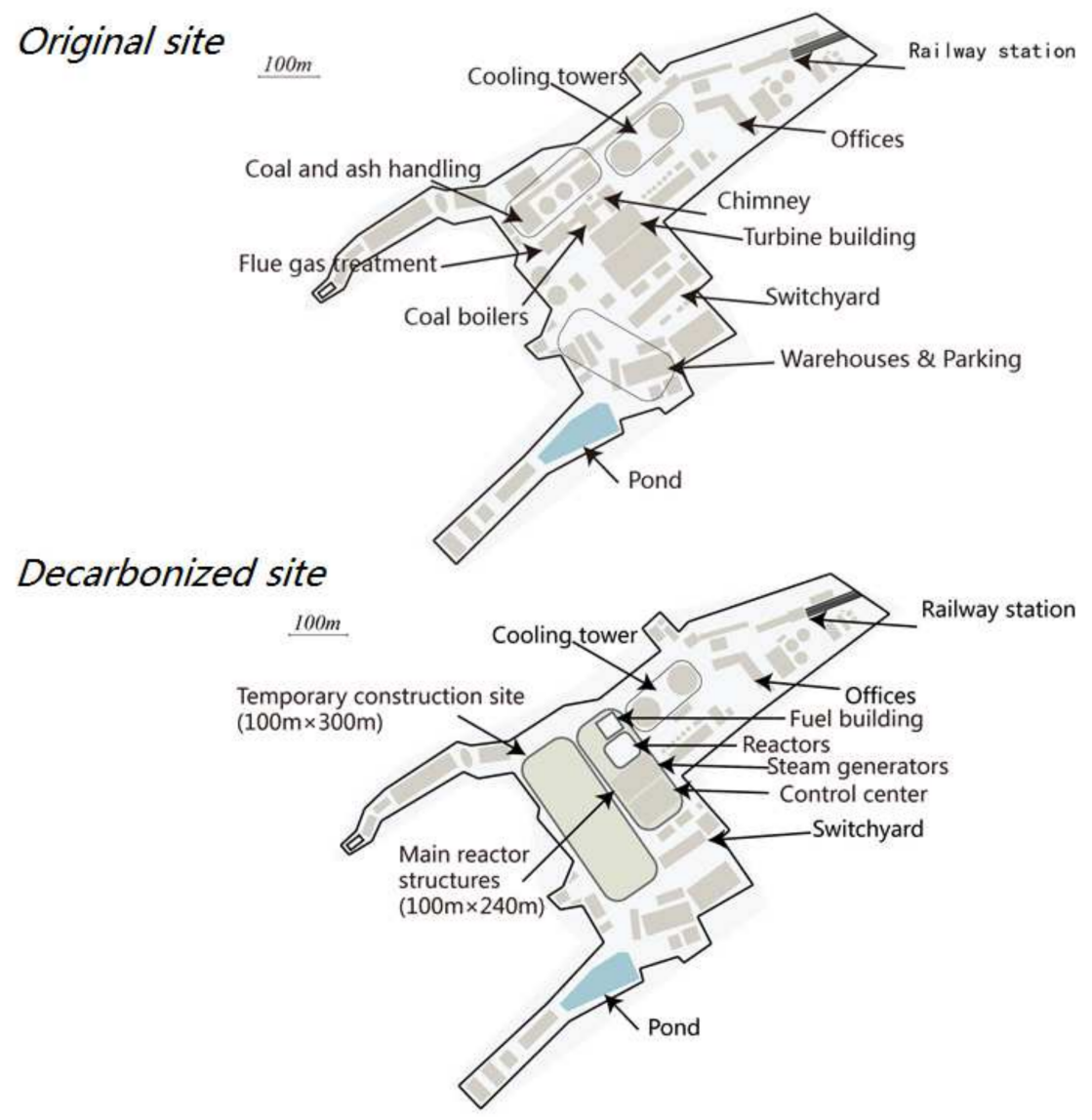

Figure A7. Retrofit decarbonization of Taishan with nuclear reactors. 


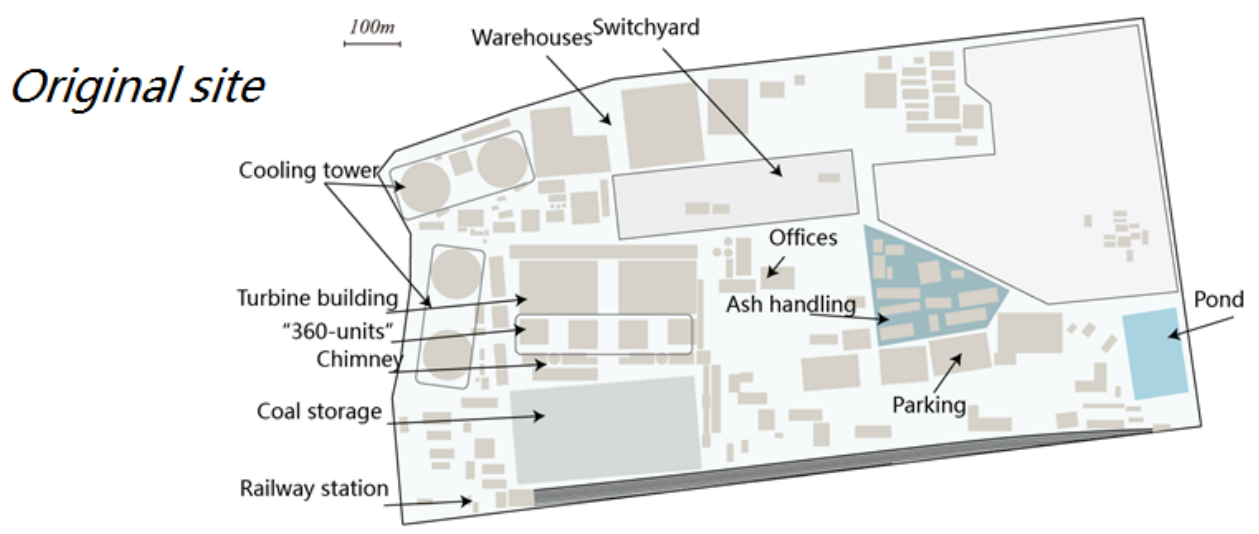

\section{Decarbonized site}

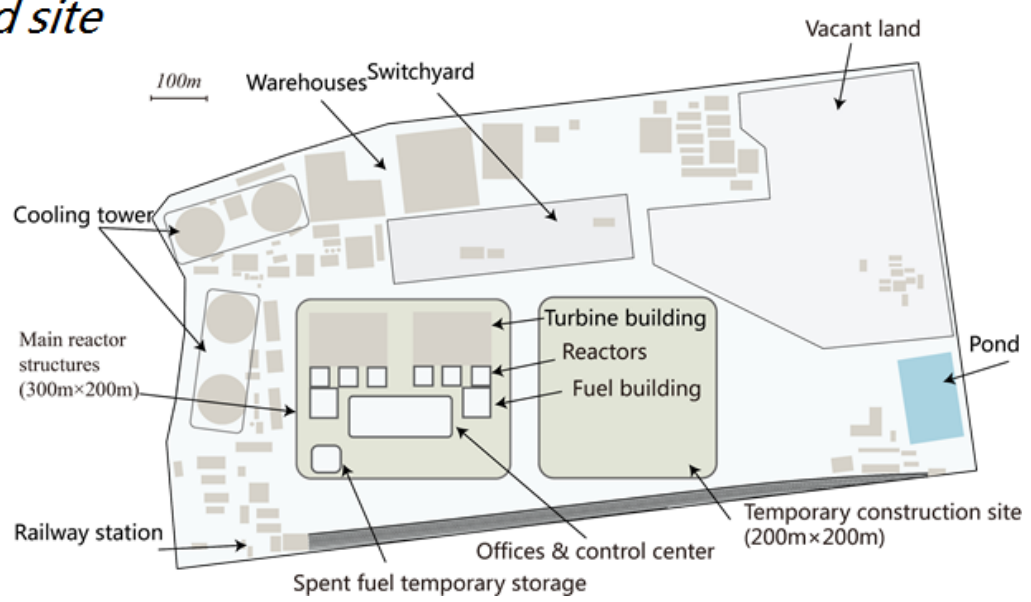

Figure A8. Retrofit decarbonization of Yangliuqing with nuclear reactors.

Original site

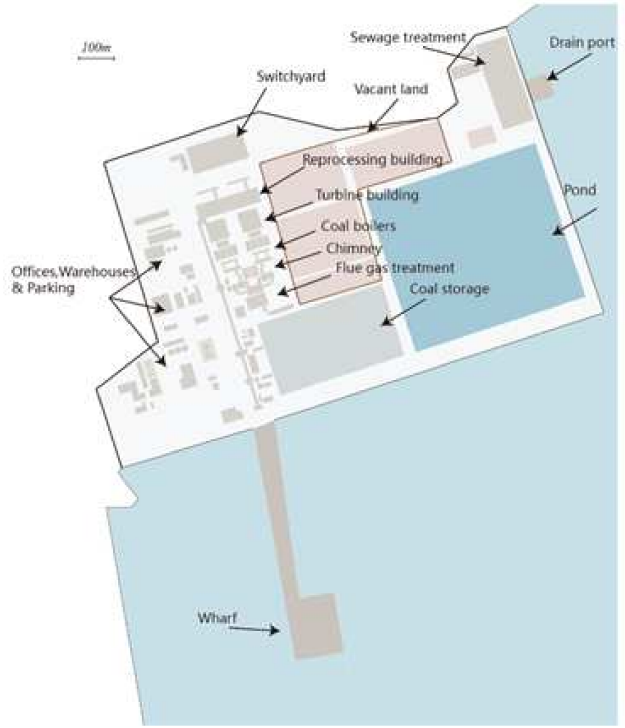

Decarbonized site

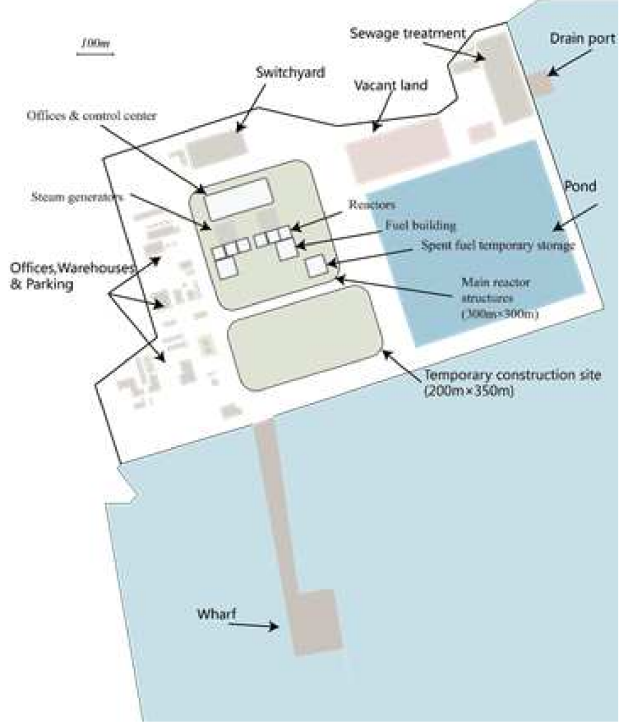

Figure A9. Retrofit decarbonization of Zhuanghe with nuclear reactors. 


\section{References}

1. Wei, Y.M.; Liao, H. Energy Economics: Energy Efficiency in China; Springer International Publishing: New York, NY, USA, 2016.

2. Hao, Y.; Chen, H.; Wei, Y.M.; Li, Y.M. The influence of climate change on $\mathrm{CO}_{2}$ (carbon dioxide) emissions: An empirical estimation based on Chinese provincial panel data. J. Clean. Prod. 2016, 131, 667-677. [CrossRef]

3. Zhao, G.P.; Yu, B.Y.; An, R.Y.; Wu, Y.; Zhao, Z.H. Energy system transformations and carbon emission mitigation for China to achieve global 2 degrees C climate target. J. Environ. Manag. 2021, 292, 112721. [CrossRef] [PubMed]

4. World Meteorological Organization (WMO). United in Science 2020 Report: Climate Change Has Not Stopped for COVID19. 2020. Available online: https://public.wmo.int/en/resources/united_in_science (accessed on 10 November 2021).

5. Party School of the Central Committee of C.P.C. Remarks by Xi Jinping at the General Debate of the 75th United Nations General Assembly. 2020. Available online: https://www.ccps.gov.cn/xxsxk/zyls/202009/t20200922_143558.shtml (accessed on 10 November 2021).

6. Chen, H.; Tang, B.J.; Liao, H.; Wei, Y.M. A multi-period power generation planning model incorporating the non-carbon external costs: A case study of China. Appl. Energy 2016, 183, 1333-1345. [CrossRef]

7. Pollitt, M.; Yang, C.H.; Chen, H. Reforming the Chinese Electricity Supply Sector: Lessons from International Experience; Working Papers; Springer International Publishing: New York, NY, USA, 2017.

8. Endcoal. Global Carbon Tracker: Coal Plants in China(MW). 2021. Available online: https://docs.google.com/spreadsheets/d/ 1mDLafuvyiLYezFmV6VXEnjlPcMy5QftwW4J2U3Qujk0/edit\#gid=0 (accessed on 10 November 2021).

9. Hoseinzadeh, S.; Heyns, S. Advanced Energy, Exergy and Environmental (3E) Analyses and Optimization of a Coal-Fired $400 \mathrm{MW}$ Thermal Power Plant. J. Energy Resour. Technol. 2021, 143, 082106. [CrossRef]

10. Liu, Q.; Chen, Y.; Tian, C.; Zheng, X.Q.; Li, J.F. Strategic deliberation on development of low-carbon energy system in China. Adv. Clim. Chang. Res. 2016, 7, 26-34. [CrossRef]

11. Wang, C.; Engels, A.; Wang, Z.J.R.; Reviews, S.E. Overview of research on China's transition to low-carbon development: The role of cities, technologies, industries and the energy system. Renew. Sustain. Energy Rev. 2018, 81 Pt 1, 1350-1364. [CrossRef]

12. Wen, Y.; Cai, B.; Xue, Y.; Wang, S.; Chen, Z.; Zhu, J.; Jiang, D.; Yue, Z. Assessment of Power System Low-carbon Transition Pathways Based on China's Energy Revolution Strategy. Energy Procedia 2018, 152, 1039-1044. [CrossRef]

13. Cheng, Y.; Zhang, N.; Kirschen, D.S.; Huang, W.; Kang, C. Planning multiple energy systems for low-carbon districts with high penetration of renewable energy: An empirical study in China. Appl. Energ. 2020, 261, 114390. [CrossRef]

14. Wen, Y.; Cai, B.; Yang, X.; Xue, Y. Quantitative analysis of China's Low-Carbon energy transition. Int. J. Electr. Power Energy Syst. 2020, 119, 105854. [CrossRef]

15. Wang, C.; Lv, C.; Li, P.; Song, G.; Li, S.; Xu, X.; Wu, J. Modeling and optimal operation of community integrated energy systems: A case study from China. Appl. Energ. 2018, 230, 1242-1254. [CrossRef]

16. Peng, H.; Qi, S.; Cui, J. The environmental and economic effects of the carbon emissions trading scheme in China: The role of alternative allowance allocation. Sustain. Prod. Consum. 2021, 28, 105-115. [CrossRef]

17. Fragkos, P.; van Soest, H.L.; Schaeffer, R.; Reedman, L.; Koberle, A.C.; Macaluso, N.; Evangelopoulou, S.; Vita, A.D.; Sha, F.; Qimin, C.; et al. Energy system transitions and low-carbon pathways in Australia, Brazil, Canada, China, EU-28, India, Indonesia, Japan, Republic of Korea, Russia and the United States. Energy 2020, 216, 119385. [CrossRef]

18. Yu, P.; Cai, Z.; Sun, Y. Does the emissions trading system in developing countries accelerate carbon leakage through OFDI? Evidence from China. Energy Econ. 2021, 101, 105397. [CrossRef]

19. Cui, R.Y.; Hultman, N.; Cui, D.; McJeon, H.; Yu, S.; Edwards, M.R.; Sen, A.; Song, K.; Bowman, C.; Clarke, L.; et al. A plant-by-plant strategy for high-ambition coal power phaseout in China. Nat. Commun. 2021, 12, 1468. [CrossRef] [PubMed]

20. Qvist, S.; Gładysz, P.; Bartela, Ł.; Sowiżdżał, A. Retrofit Decarbonization of Coal Power Plants-A Case Study for Poland. Energies 2020, 14, 120. [CrossRef]

21. IAEA. Advanced Reactors Information System(ARIS). Available online: https://aris.iaea.org/sites/overview.html (accessed on 10 November 2021).

22. Wu, Z.; Lin, D.; Zhong, D. The design features of the HTR-10. Nucl. Eng. Des. 2002, 218, 25-32. [CrossRef]

23. Tran, T.; Choe, J.; Du, X.; Lee, H.; Lee, D. Neutronic simulation of China experimental fast reactor start-up tests- part II: MCS code Monte Carlo calculation. Ann. Nucl. Energy 2020, 148, 107710. [CrossRef]

24. Wu, Y.; Bai, Y.; Song, Y.; Huang, Q.; Zhao, Z.; Hu, L. Development strategy and conceptual design of China Lead-based Research Reactor. Ann. Nucl. Energy 2016, 87, 511-516. [CrossRef]

25. Gaojian, D.; Qing, L.; Yu, L.; Danrong, S.; Dahuan, Z. Large-break LOCA analysis of CSR1000. Ann. Nucl. Energy 2021, 161, 108444. [CrossRef]

26. Zhang, Z.; Dong, Y.; Li, F.; Zhang, Z.; Wang, H.; Huang, X.; Li, H.; Liu, B.; Wu, X.; Wang, H.; et al. The Shandong Shidao Bay 200 MWe High-Temperature Gas-Cooled Reactor Pebble-Bed Module (HTR-PM) Demonstration Power Plant: An Engineering and Technological Innovation. Engineering 2016, 2, 112-118. [CrossRef]

27. Zhang, Z.; Wu, Z.; Wang, D.; Xu, Y.; Sun, Y.; Li, F.; Dong, Y. Current status and technical description of Chinese $2 \times 250 \mathrm{MWth}$ HTR-PM demonstration plant. Nucl. Eng. Des. 2009, 239, 1212-1219. [CrossRef]

28. Zhang, Z.; Ye, P.; Yang, X.T.; Ju, H.M.; Jiang, S.Y.; Tu, J.Y. Supercritical steam generator design and thermal analysis based on HTR-PM. Ann. Nucl. Energy 2019, 132, 311-321. [CrossRef] 
29. Fu, L. Approach of Operational Startup for HTR-PM in China. In Proceedings of the IAEA 64th General Conference, Vienna, Austria, 24 July 2020.

30. Ministry of Ecology and Environment of the People's Republic of China. Safety Regulations for Site Selection of Nuclear Power Plants. Available online: http://www.mee.gov.cn/ywgz/fgbz/guizhang/202001/t20200110_758622.shtml (accessed on 10 November 2021).

31. Zhao, B.; Qiu, L. Selection of emergency release source term and partition of EPZ in the Chinese PWR NPP. Radiat. Prot. Bull. 2003, 23, 6-9.

32. National Nuclear Safety Administration. “2015-2017 China's Top Ten Nuclear Science and Technology Progress" Released. Available online: http://nnsa.mee.gov.cn/ywdt/yjzx/201710/t20171026_424105.html (accessed on 10 November 2021).

33. National Nuclear Safety Administration. Hainan Changjiang Multi-Purpose Modular Small Reactor Technology Demon-stration Project Site Selection Review Opinion. Available online: http:/ /www.mee.gov.cn/xxgk2018/xxgk/xxgk09/201907/W020190717 355522387833.pdf (accessed on 10 November 2021).

34. Chinese Academy of Sciences. Public Attitudes Determine the Rise and Fall of Nuclear Power. Available online: http:/ /www.cas cn/xw/ kjsm/gndt/200609/t20060905_1002831.shtml (accessed on 10 November 2021).

35. Liu, X. Risk Attitudes and Coping Behaviors of Residents Living with Nuclear Power-Base on NDNP as An Example; Xiamen University: Xiamen, China, 2019.

36. National Energy Administration. Provisions on the Approval Procedures for the Preliminary Work of Nuclear Power Plant Construction Projects (for Trial Implementation). Available online: http://www.nea.gov.cn/2011-08/16/c_131052916.htm (accessed on 10 November 2021).

37. Ding, H.; Tong, J.; Wang, Y.; Zhang, L. Development of emergency planning zone for high temperature gas-cooled reactor. Ann. Nucl. Energy 2018, 111, 347-353. [CrossRef]

38. Data Sharing Infrastructure of National Earthquake Data Center, National Earthquake Data Center. Available online: http:/ / data.earthquake.cn (accessed on 10 November 2021).

39. Board, C.E.G. Station Planning and Design: Incorporating Modern Power System Practice; British Electricity International: Colchester, UK, 1993.

40. Strasse, W. Staffing Requirements for Future Small and Medium Reactors (SMRs) Based on Operating Experience and Projections; IAEA: Vienna, Austria, 2001.

41. Pfeiffer, A.; Millar, R.; Hepburn, C.; Beinhocker, E. The ' $2{ }^{\circ} \mathrm{C}$ capital stock' for electricity generation: Committed cumulative carbon emissions from the electricity generation sector and the transition to a green economy. Appl. Energy 2016, 179, 1395-1408. [CrossRef] 